\title{
A CRITICAL REVIEW OF OUR PRESENT KNOWLEDGE OF THE HAEMOFLAGELLATES AND ALLIED FORMS.
}

\author{
By Captain W. S. PATTON, M.B. Edinb., I.M.S.
}

A LARGE number of the trypanosomes and allied flagellates are now known to be the causal agents of some of the most fatal diseases of man and of the lower animals. The study of these parasites during the past fifteen years has truly made phenomenal strides, and at the present time it holds a position of commanding interest. Novy (1907) in a recent paper aptly states the reason for this active research when he says, "It is not merely because six or seven of these diseases have been recognised in domestic animals in Asia, Africa and South America. It is not wholly due to the discovery of a human form of the disease, but rather to the fact that the mastery by man of whole regions is called into question. The successful contest with malaria and yellow fever has now given place to the fight with trypanosomiasis and upon the issue of this struggle depends to a large extent the destiny of Equatorial Africa."

Of the numerous publications upon the Haemoflagellates the first to occupy our attention is one of recent date by Woodcock (Jan. 1909). Except for a few additions relating to recent work Woodcock's article is identical with a similar one which appeared in the Quarterly Journal of Microscopical Science for 1906. This in itself is disappointing for we understand that Dr Woodcock, as Mackinnon Student of the Royal Society, has been working for the last two years at the Haematozoa of birds and their relation to certain Haemoflagellates; yet very little convincing evidence is now brought forward to support Schaudinn's conclusions.

We propose reviewing in detail Woodcock's present article, which is divided into eight sections, a postscript, an appendix and a complete list of the known hosts of the trypanosomes and allied forms. In his 
introductory remarks Woodcock states, that although the trypanosomes possess a common uniform type of organisation, they probably do not all belong to a single well-defined group of monophyletic origin, but are better regarded as an assemblage of forms which have sprung from quite different stocks. Their resemblance he regards as being brought about by the acquirement of similar adaptations to similar highly specialised modes of life. Later on we shall see that there is at present very little evidence in support of the many hypotheses on the origin of these parasites.

Haemoflagellates with two flagella, one directed anteriorly, and the other attached to the body of the parasite by an undulating membrane, Woodcock regards as being derived from a Heteromastigine ancestor. Those flagellates which only possess a single flagellum being derived from a Monadine ancestor; some of these however are to be looked upon as originating from a Heteromastigine form. All these flagellates possess a principal nucleus named by Woodcock the trophonucleus, and a smaller chromatic body, the blepharoplast, which Woodcock has named the kinetonucleus. The parasites divide by binary longitudinal fission or by multiple segmentation; very little however is known of their life cycles. The author gives a short account of the earlier work that has been done on the structure and life histories of the trypanosomes and pays a warm tribute to the great value of the Romanowsky stain and its many modifications. This is pleasing to read from the pen of a zoologist, as it was feared these valuable stains would have been condemned for the more recent wet methods now in vogue.

In the next section, Woodcock deals with the occurrence and transmission of trypanosomes, and notes that so far the majority have been found in mammals, birds and fishes, but a few have been described from amphibians, while among reptiles their occurrence has only been observed in one or two instances. In a recent paper Wenyon (1908) has described an interesting flagellate from the blood of a snake, Erythrolamprus aesculapii; this parasite is very suggestive of a true Crithidia. We are however at present unable to express a definite opinion on its nature.

Woodcock draws attention to the distinction between the true or natural hosts of trypanosomes and the strange or casual ones, and notes that when certain trypanosomes are injected into strange hosts, the latter readily succumb. This is naturally to be expected; it is difficult to understand any trypanosome not being pathogenic although the lesions it produces may not be gross. On more than one occasion we 
have seen rats (Mus decumanus) succumb to an infection of T. lewisi and Jürgens (1902), Francis (1903) and others have made similar observations. The subject however is complicated by the production of active immunity against trypanosomiasis, and it is not therefore possible with our present limited state of knowledge to draw any final conclusions from the facts already ascertained.

Except in the case of $T$, equiperdum, trypanosomes are transmitted from one vertebrate host to another, through the intermediation of a blood-sucking invertebrate. Woodcock notes that the actual relations existing between any particular trypanosome and its transmitting invertebrate are at present uncertain, but that in most cases the invertebrate acts as a true host. According to Woodcock the investigations of Léger (1904), Brumpt (1906) and Keysselitz (1906) have made it clear that the trypanosomes of fishes undergo a definite evolutionary cycle in particular organs of leeches which have fed on the infected fish. The development however can only proceed to its fullest extent in a certain leech. For example, $T$. granulosum of the eel only undergoes its cycle of development in Hemiclepsis marginata; in other leeches, such as Callobdella punctata, Hirudo troctina and Piscicola geometra, the parasites only undergo partial evolutionary changes and then die off. This restriction, Woodcock says, distinctly points to the leech in question (Hemiclepsis) being the specific natural host of $T$. granulosum. It is true that Brumpt has succeeded in infecting healthy fish with trypanosomes by placing on them leeches already infected with the parasite; these experiments however by no means prove that this is the only method by which trypanosomes are transmitted from one fish to another. Thomson (1908), who has recently studied a trypanosome of gold fish, was unable to find a single leech on any of the fish from a particular pond, although a large number of fish were examined, the majority of which were infected. These observations clearly suggest that piscine trypanosomes may be transmitted by some method other than by the bites of leeches.

According to Schaudinn's (1904) researches $T$. noctuae undergoes its developmental cycle in Culex pipiens and there is a regular periodicity in the infectivity of the mosquito. Prowazek has also described the development of another vertebrate trypanosome $T$. lewisi in the rat louse Haematopinus spinulosus; and considers this insect acts as a true alternate host of T. lewisi. We would draw attention to Nuttall's (1908) recent transmission experiments with this parasite in which he clearly demonstrates that it is transmitted from rat to rat by means of Cera- 
tophyllus fasciatus, Ctenophthalmus agyrtes and Haematopinus spinulosus. It is obvious from these experiments that neither of these blood-sucking insects are true alternate hosts of $T$. lewisi, more especially as it was not possible to demonstrate any developmental cycle of the rat trypanosome in their alimentary tracts.

It has been definitely established by Bruce, Nabarro and Greig (19031907 ) that tsetse flies can only transmit certain pathogenic trypanosomes of Africa up to forty-eight hours after feeding on an infected animal. Precisely similar results have been recorded by Minchin, Gray and 'Tulloch (1906), and in addition they ascertained by actual experiments that only the first animal upon which the infected fly fed became infected. These facts prove conclusively that these trypanosomes are conveyed by tsetse flies in a purely direct and mechanical way (see Appendix for Bruce's recent work). Minchin (1908) has however recently brought forward certain observations which suggest that $T$. gambiense undergoes some multiplicative changes in the alimentary tract of $G$. palpalis. After forty-eight hours the trypanosomes ingested by the fly are differentiated into two types which Minchin considers represent sexual forms; after ninety-six hours they however degenerate and disappear. It is impossible to say whether these changes represent part of the developmental cycle of $T$. gambiense. Koch (1906-07) also claims to have shown that $T$. brucei when ingested by G. fusca and G. tachinoides undergoes a true evolutionary cycle in the alimentary tracts of the flies, and lastly Stuhlmann (1907) has described what he considers to be the development of T. brucei in $G$. fusca bred in captivity. Woodcock, remarking on the above observation, says, that there is good reason to suppose that for a given pathogenic trypanosome there is a particular insect, which is a true alternate host, and that here, as among leeches, there are right and wrong hosts. He concludes this section by drawing attention to Minchin's (1908) recent hypothesis on the method of infection of trypanosomes. It will be remembered that this author's view is based on the discovery of the encystment of one of the flagellates of $G$. palpalis in the proctodaeum of the fly. As the transmission of trypanosomes is intimately connected with their life cycles we shall deal fully with this subject when considering the section devoted to the life cycles of these parasites.

In the section devoted to the habitat and effects of trypanosomes on their hosts, vertebrate and invertebrate, Woodcock first refers to Schaudinn's observations on T. noctuae in Culex pipiens; the extensive migration of the flagellates in the mosquito are quoted as an example 
of the habitat of trypanosomes in an invertebrate host. We will criticise Schaudinn's observations in this connection further on. Prowazek's (1905) work on the development of T. lewisi in Haematopinus spinulosus is next described and the migrations of the so-called developmental forms of T. lewisi in the louse are said to agree in the main with Schaudinn's observations. Mammalian trypanosomes however have so far only been found in the alimentary tracts of tsetse flies; but Koch believes that the flagellates he found in the salivary glands of certain Glossinae are identical with T. gambiense. This is however by no means proved.

Woodcock next refers to Brumpt's (1906) work on the development of piscine trypanosomes in leeches, and notes that they also are restricted to the alimentary tracts of these invertebrates; in a footnote Brumpt's (1907) later observations on the hereditary transmission of certain leech trypanosomes are mentioned. According to Brumpt three kinds of behaviour of trypanosomes in leeches can be distinguished. (a) The parasites develop solely in the stomach of the leech and never pass into the intestine or sheath of the proboscis; this is the method of development of T. remaki. (b) In the case of T. granulosum the development begins in the stomach of the leech and is continued in the intestine, where the parasites may remain for a long time; they then pass back again to the stomach and later to the proboscis sheath. (c) This method of development goes on in the stomach, the parasites, T. danilewskyi, in time finding their way back to the sheath of the proboscis. T. raiae and T. scylli, which, according to Brumpt, develop in Pontobdella, undergo their evolution in the stomach and intestine of the leech, but Brumpt was unable to ascertain how they passed back again into the fish. Miss Robertson (1907) has recently described what she considers to be the development of $T$. raiae in Pontobdella muricata. We shall criticise these views regarding developmental cycles of piscine trypanosomes in the section dealing with the life histories of these parasites.

With regard to the effect of trypanosomes on vertebrate hosts, Woodcock gives a short resumé of the train of events in an infection with one of these parasites. We note however that Salvin-Moore and Breinl's (1907-08) recent work on T. gambiense, T. equiperdum and T. lewisi is only just referred to. We consider this work should have been described in detail. Woodcock draws attention to the great variation in the size and shape exhibited by many trypanosomes and states that in some instances at any rate sexual differentiation is 
expressed by more or less pronounced differences in appearance. This is a very loose statement and should certainly be qualified, anyone reading it for the first time might be led to believe that the sexual types of trypanosomes are well established. As far as we can gather, sexual differentiation among these parasites is purely arbitrary, and there is not the slightest proof to show that certain short forms with coarsely granular cytoplasm are female parasites, while the more slender trypanosomes with few granules are males. That these forms represent true sexual differentiation and that the parasites conjugate to produce zygotes has yet to be proved (see Dctlein, 1909).

We think Woodcock wisely refers to the two ends of a trypanosome as the flagellate and non-flagellate, we however do not doubt that the flagellate end is the anterior; it certainly is in Herpetomonas and Crithidia. Two remarkable figures of $T$. lewisi from the blood of a recently infected rat are given; their posterior ends are drawn out to a great length tapering to a point. Woodcock states that in such forms the flagellum is very short; we must admit we have not seen this stage of $T$. lewisi. About the fifth to the ninth day after a rat is inoculated with this trypanosome, young developing parasites are usually found in large numbers in its peripheral blood, and we have frequently noted that they may be readily distorted in making a blood film, particularly if it is fixed by the wet method.

In discussing the minute structure of trypanosomes Woodcock again appeals to Schaudinn's work and reproduces his figures of the development of an indifferent trypanosome ( $T$. noctuae) from a halteridium ookinete. Salvin-Moore and Breinl (1907) have recently questioned the correctness of Schaudinn's interpretation of the appearances seen during the division of the nucleus of a trypanosome, claiming that the chromosomes are produced by the fixing and staining methods employed and that they are probably artefacts. If, as we believe, most of Schaudinn's figures represent changes in the development of certain insect flagellates, we have no doubt that their nuclei contain definite chromatic bodies, but whether these are true chromosomes is at present in our opinion of little importance.

Woodcock states there is no reason to doubt that the blepharoplast of a trypanosome is not merely an extra-nuclear centrosome, but a true nucleus homologous with and equivalent to the principal nucleus, and that there are distinct centrosomes connected with both blepharoplast and nucleus. The former he considers has an extra-nuclear centrosome at the base of the flagellum, and the latter an intra-nuclear 
one. Salvin-Moore and Breinl, on the contrary, consider the blepharoplast is an extra-nuclear centrosome; Woodcock however considers that this view is not supported by the evidence furnished by the trypanoplasmes.

In the present state of our knowledge we think it would be of very little use to discuss the pros and cons of these disputes; we consider however that it is by no means proved that the trypanoplasmes afford any evidence on the structure of the trypanosomes. All the evidence so far collected (see p. 124) clearly suggests that true trypanosomes have originated from crithidia-like ancestors, and we believe that the study of these simple insect parasites will be a valuable guide to the study of the structure and origin of the trypanosomes. Quite recently the writer found a new flagellate in the Malpighian tubes of Musca domestica; this parasite is even more primitive in its morphology than any flagellate yet described, as its flagellum is entirely wanting and appears to be replaced by a simple elongation of its ectoplasm. It is hoped that the study of this parasite will throw some light on the nature of the flagellum and its connection with the blepharoplast; at present we think it is premature to theorize on the nature of these chromatic structures.

In the section devoted to biological considerations Woodcock remarks on the various movements exhibited by trypanosomes and notes there is a great difference of opinion as to whether the flagellum or the undulating membrane play the principal part in the movements of trypanosomes. It has always appeared to us that the flagellum is the chief factor in the movement of these parasites, and this is very evident when living Herpetomonads are studied. We have seen many which travel quite as fast as T. lewisi.

With regard to the peculiar phenomenon known as agglomeration, Woodcock states that, in the case of vertebrate trypanosomes, the parasites collect together by their aflagellar ends, forming a multiple union or rosette. In Trypanosoma noctuae according to Schaudion the parasites agglomerate by their flagellar ends. A great deal of confusion is here introduced by the use of the term "rosette"; by this term we understand a group of parasites which have resulted from the multiple segmentation of a single cell. In cultures of T. lewisi (figured by Laveran and Mesnil, 1904) and in Herpetomonas culices (figured by Patton, 1907) the flagella are directed centrally; it should be noted these parasites are not adult flagellates. In the multiplication rosette of $T$. lewisi from the blood of a recently infected rat the flagella are directed 
externally. In the case of the rosette of Crithidia gerridis the flagella are similarly directed externally, while in the agglomeration of the adult flagellates the flagella are directed centrally. The explanation of the position of the flagella in a true multiplication rosette is always readily ascertained by studying the method of multiple segmentation. In our opinion the agglomerated cluster of male forms of $T$. noctuae from the intestine of Culex pipiens as figured by Schaudinn represents a true Herpetomonad rosette. We think it is of some importance for a beginner to have a clear conception of the difference between a true multiplication rosette of a Trypanosoma, Herpetomonas and Crithidia and a mere agglomeration of adult flagellates, which is quite a distinct process.

It is not possible to say why adult vertebrate trypanosomes collect together (see p. 118) by their aflagellar ends under certain conditions. We have certainly not seen insect flagellates collect together by their aflagellar ends in the alimentary tracts of their hosts.

Woodcock considers the abnormal and involution forms of trypanosomes are produced as a result of chromatolysis, vacuolisation and change of form. In the light of Salvin-Moore and Breinl's recent work these round or oval bodies represent an important phase in the life cycle of a trypanosome; if this proves to be the case it opens up an entirely new field of research.

We now propose dealing with the most important section of Woodcock's article, the life cycles of trypanosomes, and we have pointed out above that it is intimately connected with the transmission of these parasites from one host to the other. When Woodcock wrote his first article on the Haemoflagellates Schaudinn's observations on the life cycle of $T$. noctuae appeared to be amply corroborated by the brothers Sergent (1905), Billet (1904), Brumpt (1904), Léger (1904) and Rogers (1904); we do not see however what connection the parasite of Kala-Azar has with Schaudinn's work and how Rogers' discovery of its flagellate stage has corroborated it. Woodcock evidently still thinks this parasite is a Piroplasma in spite of recent researches.

Since the publication of the paper by Novy and MacNeal (1905) describing valuable work on the trypanosomes of birds, Schaudinn's work has been largely discredited. Influenced still further by their researches on mosquito flagellates, Novy and his collaborators have expressed the view that the Haemoflagellates and Haemosporidia are quite distinct, and that the trypanosomes of vertebrates do not undergo any developmental cycle in insect hosts. In spite of what Woodcock says to the 
contrary, that recent researches are in favour of vertebrate trypanosomes having specific alternate invertebrate hosts, we hope to show that the views of the American observers hold good at the present time. Woodcock then proceeds to describe the researches which support his contention.

According to Léger (1904), Trypanoplasma varium, in the blood of the loach, may be differentiated into ordinary (indifferent) forms and large, more granular (probably female) parasites. When these parasites were ingested by Hemiclepsis sp.? the indifferent forms degenerated and died out, the female parasites however became more massive and exhibited nuclear changes which Léger thinks suggest a sexual process. After some days the intestine of the leech contained numerous little narrow trypanoplasmes, some of which were filiform (male), while others had a kind of beak which made them resemble trypanosomes. These observations were published in a preliminary note without figures so that we are unable to refer to the actual appearances of the parasites. We know of no subsequent work confirming Léger's observations. In this preliminary note we are not told how Trypanoplasma varium developed into the male forms he describes from the leech; where the evolution of the one begins and the other ends is not at all clear. If these changes take place naturally in the leech it is surely possible to trace all the stages from the unchanged female forms up to the formation of the narrow trypanoplasmes and the parasites with beak-like processes; if not there must be some other explanation for the origin of these forms. We can find no reference to the possibility of Hemiclepsis being infected with a natural flagellate. We are therefore unable to accept this developmental cycle of Trypanoplasma varium as proved.

Woodcock next describes Léger's (1904) observations on Trypanosomabarbatulae in another leech, Piscicola. Léger, it will be remembered, draws particular attention to the formation of male, female and neutral forms of this parasite and says they correspond exactly with Schaudinn's three types. Woodcock states thut these types are sharply differentiated in the invertebrate host and less so in the vertebrate. Here again we fail to see what connection these so-called male, female and indifferent forms in the leech have to do with T. barbatulae. The existence of these forms is certainly not proved in Léger's paper, a natural flagellate of Piscicola is not referred to, nor is it shown how the trypanosome gets back again to the fish. In his original article on the Haemoflagellates Woodcock says, "the above-stated facts however hardly leave room for doubt that both these piscine trypanosomes have a true alternating 
Hirudinean host." We consider there is a great deal of room for doubt.

Woodcock next deals with Brumpt's (1906) observations on the development of T. granulosum in Hemiclepsis marginata. Brumpt has given no figures showing how this trypanosome develops into the pyriform parasites in the stomach of the leech; the description of these pearshaped parasites in the leech clearly suggest a Crithidia similar to what we have seen in a species of Glossiphonia. Brumpt also states that the Herpetomonad forms of $T$. granulosum remain for months in the stomach of the leech; this fact again suggests a natural flagellate; we have found these flagellates remain for at least five months in the crop-diverticula of a leech. Brumpt states that the parasites in the leech eventually produce trypanosome-like forms which find their way to the foremost stomach coeca and proboscis sheath by the fifth day. With regard to this observation, Woodcock says, "these are the forms which are inoculated into the eel, becoming by simple elongation ordinary T. granulosum again." Anyone reading this statement might be led to believe that this has been proved by Brumpt, whereas this is by no means the case. Before it can be proved that the flagellates in the stomach of the leech were actually injected into the blood of the eel, Brumpt must demonstrate the change from one parasite to the other; it is also necessary to show that the leech has not got any unchanged $T$. granulosum in its proboscis sheath. Throughout these observations of Brumpt we can find no reference to the exclusion of a natural flagellate of Hemiclepsis; this is surely necessary.

Woodcock gives a detailed account of Miss Robertson's (1907) researches on a flagellate from the alimentary tract of Pontobdella muricata; with her, he regards it as representing the developmental forms of $T$. raiae. According to Woodcock, Brumpt has found that T. raiae does develop in Pontobdella. In an earlier paper we (1908) pointed out, after reading Miss Robertson's account of the life history of the flagellate of the leech, that the flagellate in question was most probably a true parasite of the leech. The structure of the adult flagellate and the method of development of its flagellum clearly suggest that this parasite is a true Crithidia -it is not at all unlike some of the tsetse fly crithidia-we have therefore named it $C$. robertsoni. All the evidence goes to show that this flagellate of Pontobdella is transmitted hereditarily. We can find nothing in Miss Robertson's or Brumpt's papers to show that it represents any stage in the evolution of T. raiae. Neither of these authors have attempted to exclude a natural flagellate of Pontobdella, and before this has been done 
we do not see how it is possible to say T. raiae undergoes a true developmental cycle in Pontobdella muricuta. Wuodcock in criticising Miss Robertson's very cautious remarks regarding the process of conjugation of this flagellate boldly says, "it is more probable that conjugation itself takes place soon after the transfer of the parasites from one host to the other, i.e. after the arrival in the invertebrate; and that the ookinete form is the immediate result of the process." It is difficult to understand these wild speculations; such hypotheses, based as they are on erroneous conclusions, can hardly help forward this difficult subject. They are certainly not suggested by Léger's work on T. barbatulae, or Prowazek's (1905) work on T. lewisi in the louse.

Woodcock next shortly describes Keysselitz's (1906) work on the development of Trypanoplasma borreli in Piscicola geometra. According to that author, male and female gametes can readily be recognised in the blood of the carp, conjugation taking place in the leech and later giving rise to the three general types of Schaudinn. We (1909) have elsewhere shown that Keysselitz's developmental cycle cannot be accepted; he has not rigidly excluded a natural flagellate from the leech and his observations are therefore of little value. From his description we are unable to ascertain how Irypanoplasma borreli passes into the developmental forms in the leech. We therefore consider these parasites represent part of the life cycle of a Crithidia of the leech; the fact that Keysselitz found that leeches caught at large contained these flagellates assuredly suggests this. We would like to know whether any experiments were conducted to exclude a flagellate transmitted hereditarily.

In a recent paper Miss Robertson (1908) claims to have traced the development of a trypanosome of Emyda vittata in a leech. She states that the development is similar to what takes place on a slide (sic), and which is shortly as follows: "the trypanosome rolls itself up and the flagellum breaks free, but generally still remains attached at the kinetonucleus end. The flagellum is motile for a long time, but finally comes to rest, lying often in an untidy tangle round the creature. The trypanosome divides into two, the daughter individuals generally remaining more or less in contact; a fưrther division into two occurs; the divisions in every case involve both the tropho- and the kineto-nucleus. The result of these divisions is a group of four often very irregular little creatures; they become pear-shaped and put out each a flagellum from their blunt ends and this gradually lengthens and becomes motile, but at first it is quite unable to move the body of this creature. The four little flagellates separate and move actively about." From this 
very untidy description we gather that this trypanosome merely undergoes a process of multiplication exactly similar to that of $T$. lewisi, $T$. rotatorium, and others in cultures. We cannot regard this as a true developmental cycle and therefore the leech cannot be a true alternate host; no sexual cycle appears to be necessary. We note there is no mention of the possibility of the leech in question having a natural flagellate in its alimentary tract; perhaps Miss Robertson will show in her next paper that such a flagellate has been carefully excluded. If not we must doubt even this method of multiplication of $T$. vittatae.

All the above authors in their researches on the development of piscine and reptilian trypanosomes and trypanoplasmes in leeches have failed to exclude their natural flagellates; their descriptions also of the various life cycles are far from convincing. Some of the parasites appear to have a sexual cycle, while others have dispensed with the sexual process, and merely multiply asexually. Much of the work requires confirmation and reinvestigation. It is quite unjustifiable to draw any far-reaching conclusions from what we consider to be erroneous observations.

With regard to Prowazek's (1905) work we have recently criticised it and shown that there is no evidence to support the view that T. lewisi undergoes a developmental cycle in Haematopinus spinulosus; we consider Prowazek's developmental forms represent a part of the life cycle of a true Crithidia of the louse. Referring to the development of other mammalian trypanosomes in tsetse flies, Woodcock describes the work of Minchin, Gray and Tulloch. Minchin (1908) in a recent paper has drawn attention to the polymorphism exhibited by T. gambiense in the blood of a rat; two of the types he regards as sexual forms; there is however no proof that this view is correct. It has yet to be proved that these types represent male and female trypanosomes. We do not think there is the slightest evidence that these so-called male and female parasites conjugate soon after they pass into the stomach of an insect. Stuhlmann (1907), in his work on the development of T. brucei in G. fusca, has not described the male, female, and indifferent forms of the parasite of Nagana as depicted by Prowazek (1905); nor does he refer to the formation of ookinetes at the beginning of the infection of the fly. The first parasites be found in $G$. fusca were of the neutral type, which occurred in large numbers in the midgut of the fly. Woodcock thinks Stuhlmann probably missed some early essential phases of the development, for Léger found ookinetes of $T$. barbatulae in the leech eighteen hours after it had fed. According to Stuhlmann the indifferent para- 
sites spread forward to the proventriculus where they became long forms, which Woodcock regards as corresponding with the slender forms of the flagellate of Pontobdella muricata.

In the proboscis of freshly caught tsetse flies Stublmann found little crithidial forms, which he regards as the stages of the parasite which are destined to pass back to the vertebrate. He however was unable to infect any vertebrate with $T$. brucei by injecting these parasites into them. Woodcock in trying to explain this discrepancy says, "There is some other, as yet unknown, factor or condition concerned in this perplexing question." We consider the perplexity arises from the fact that Stublmann failed to recognise the possibility, in fact certainty, of $G$. fusca being infected with a natural flagellate. Stuhlmann bred G. fusca from pupae and concluded the flies were free from infection, in other words, that hereditary transmission of the flagellates of tsetse flies does not take place. We can find nothing in Stuhlmann's paper proving this to be the case. Why did he not examine the alimentary tracts of the pupae for flagellates or their earlier stages? This should certainly have been done. Further, careful control experiments by feeding flies on clean animals should have been carried out and they should then have been examined for flagellates, but this appears to have been overlooked. All subsequent observers have accepted Stuhlmann's observations and have not attempted to exclude a natural flagellate of $G$. fusca. It is quite obvious Keysselitz and Mayer (1908) have fallen into this trap.

It will be remembered that Stuhlmann fed his raised G. fusca on animals infected with T. brucei and from two to four days later found that $80-90 \%$ of the flies were swarming with flagellates. He then describes these flagellates as representing the cycle of development of T. brucei. A careful reference to his description and figures leaves us to imagine how T. brucei comes to develop into the flagellates of the fly. The masses of flagellates lining the intestinal epithelium clearly suggest a natural parasite, and to anyone who has studied a large number of these parasites this is at once evident. We therefore cannot accept this work as being accurate, and we regard his developmental forms as a true Crithidia of G. fusca which is transmitted hereditarily.

Minchin (1908), in his work on the development of Crithidia grayi in G. palpalis, describes three forms of this flagellate: (1) the ordinary type having a multiplicative function and giving rise to the swarms of parasites often found. It is usually of large size, and the blepharoplast shows great variability in its position; Minchin thinks this form most nearly 
represents that in which $T$. grayi occurs in its vertebrate host (avian). (2) This type is constituted by slender, elongated parasites with welldeveloped undulating membrane and flagellum; it occurs chiefly in the hind gut of the fly. (3) Very narrow thin forms of a typical Herpetomonad structure with practically no undulating membrane. The parasites were found in the proctodaeum and produced the cysts of T. grayi.

In criticising the above work we would like to first point out that we do not agree with Minchin that this flagellate of $G$. palpalis has anything to do with a vertebrate trypanosome, but that it is a natural Crithidia of the fly. Minchin's hypothesis as to its origin is based solely on the habits of the tsetse fly; beyond certain observations on the feeding habits nothing is known of the behaviour of tsetse flies at their breeding grounds. In his recent paper Minchin (1908) dismisses Novy's original suggestion, that $T$. grayi is a fly parasite, by saying: "At the present time true trypanosomes are only known to occur in the blood of vertebrates, and in the stomachs of insects which suck the blood of vertebrates; hence, it is reasonable to assume that the insects in question obtain their trypanosomes from the vertebrates. When trypanosomes have been found in plant juices or stagnant waters it will be time enough to speculate on the possibility of blood-sucking insects obtaining them from such sources." Has Minchin studied this parasite, or any similar flagellate which encysts in the rectum of a blood-sucking insect, sufficiently to justify this statement? Did he, while in Uganda, endeavour to find the cysts of $T$. grayi in the faeces of $G$. palpalis in his fly cages, on twigs or even in plant juices or other places where the flies might deposit their excreta? We can find no reference to this in his paper. We would like to point out to him that we do not expect to find trypanosomes in plant juices or stagnant waters, but the cysts of a Crithiaia, which is a very different thing. We have shown that these flagellate cysts are well adapted for an extracorporeal existence and that they can resist desiccation. We will here refer to one parasite which we have studied and which fully bears out our view. While making a study of $H$.culicis in $C$. pipiens and $C$. fatigans we found the encysted stages of the flagellate in the rectum of the mosquito as well as in its excreta. Exactly similar bodies were recovered from the alimentary tracts of the larvae of the insects. A study of the habits of the mosquito clearly explained the method of infection. The mosquitoes in one particular tank collected in large numbers in a dark corner just above the water were they subsequently laid their eggs. They were to 
be found here in the day digesting the blood they had sucked the night before and undoubtedly passed their faeces into the water. Without actually finding the cysts of $H$. culicis in the water it was quite evident that the larvae ingested them accidentally while feeding on the surface of the water. We would draw Minchin's attention to these observations, for we believe, that if a careful study of the habits of the tsetse fly at its breeding grounds had been carried out, it would have been found that the flies accidentally ingest the cysts passed out in the faeces of other flies. A careful search should have been made in the alimentary tracts of a large number of specimens of G. palpalis for the cysts and the early stages of their development. Flies bred in captivity should have been placed in cages with wild flies to see if they became infected. One experiment carried out by Minchin suggests that this actually took place; he however interprets it in quite another way because the fly was unfortunately fed on a fowl. We are not even told whether this fowl had trypanosomes in its blood; this is a strange omission.

Before concluding that $T$. grayi undergoes the complicated cycle as suggested by Minchin, it would have been wiser to have first excluded a simpler and more natural life cycle such as we have suggested. Such complicated cycles are not common in nature. We believe that if T. grayi had been studied along the lines we have suggested the confusing number of forms described and figured by Minchin would have fallen into their natural places. We cannot agree with him in his description of the Herpetomonad forms. The flagellates he depicts as such are certainly not like a Herpetononas; their anterior ends are drawn out along the flagella, clearly pointing to the presence of a narrow undulating membrane (see figures of $C$. gerridis). No Herpetomonas has this appearance. T. grayi we would then regard as a natural flagellate of G. palpalis belonging to the genus Crithidia; it is transmitted from one fly to the other by means of cysts which are accidentally ingested by other flies. The Crithidia of G. fusca on the other hand is transmitted hereditarily, and this accounts for the differences in the methods of development of the two parasites which have so perplexed Minchin, Stuhlmann and others.

\section{Mode of Transmission of Trypanosomes by Tsetse Flies.}

In an earlier part of this paper we pointed out that the study of the life cycles of trypanosomes was intimately connected with the elucidation of the methods by which they are transmitted in nature. In the course 
of our criticism of the so-called developmental cycles of certain vertebrate trypanosomes in tsetse flies we have clearly shown that there is no evidence to support the views of those who maintain that these parasites of Africa undergo a true evolutionary cycle in the alimentary tracts of the flies. We firmly believe that Koch, Minchin, Stublmann, Keysselitz, Mayer and Roubaud have all confused these vertebrate trypanosomes of Africa with the natural Crithidia of the Glossinae and that therefore their conclusions are erroneous and misleading:

Owing to the great importance of knowing exactly how these pathogenic trypanosomes are transmitted to man and the lower animals, we now propose reviewing in detail the many observations that have been recorded. In order to make the subject quite complete it is necessary to begin with Bruce's (1896) experiments in Zululand. It will be remembered that Bruce on capturing some Glossinae (G. morsitans and probably $G$. pallidipes) kept them for a few days (exact time not being stated) and then fed them continuously on the same dog; in all, three such experiments were carried out. In one case five flies were fed on the same dog (1) every second day for nine weeks; in the second experiment, thirty flies were fed every day for ten days on the same $\operatorname{dog}(2)$ and in the third experiment fifty flies were fed daily for fourteen days on another dog. As a result of these three experiments Bruce found that none of the dogs became infected with $T$. brucei. It should be noted Bruce does not mention the length of time the flies were kept before they were fed on the dogs.

Bruce then carried out another series of experiments, this time feeding tsetse flies (presumably G. morsitans) on Zulu dogs infected with T. brucei and obtained the following results :

1. Interrupted feeding. In one case infection occurred after thirtytwo feeds fifteen days after the first feed and in another case after twenty-four feeds with an incubation period of eight days.

2. Twelve hours interval. A dog became infected after nine flies had been fed 333 times.

3. Twenty-four hours interval. Twelve flies were fed on alternate days about 228 times and produced an infection in thirty-eight days.

4. Forty-eight hours interval. Twelve flies were fed on a dog for thirty-one days, seventy feeds were necessary before infection was produced.

5. Three days intervals gave negative results.

Bruce's experiments then clearly demonstrate that quite a small number of ties (G. morsitans) are able to infect clean animals immediately 
after they had sucked the blood of an infected animal; and further that such infection can be produced up to an interval of forty-eight hours after sucking infected blood. Bruce also carried out one experiment (No. 225) in order to answer the question: "Is the tsetse fly capable of giving rise to the disease if taken out of the fly country into a healthy locality?" Bruce collected Glossinae in the low-lying fly country in the early morning, took them up to his camp on the top of Ubombo and immediately fed them on a healthy animal which subsequently became infected. It is presumed that these flies had already fed on an animal infected with $T$. brucei and that while they were feeding for the second time on a clean animal they were captured; yet when fed a third time on Bruce's clean animals on Ubombo they produced the infection. Remarking on these experiments Minchin (1908) says: "in our experiments on direct transmission, already recorded (loc. cit.p. 244), we found that if the fly, after feeding on an infected animal, were fed on two healthy animals in succession, only the first healthy animal became infected, not the second-that is to say, that by puncturing the skin of a healthy animal the proboscis is 'cleaned' for a second one. Hence, if the infection of T. brucei were only by the direct method, the flies caught off a healthy animal, in Bruce's experiment, should have been non-infective. The experiment seems to me, therefore, to indicate that in the case of $T$. brucei there is infection of a type other than the direct - that is to say, that cyclical infection occurs doubtless in addition to direct infection."

In a recent paper Kleine (1909) records some observations which seem to show that distant transmission, presumably after a developmental cycle, takes place in the case of T. brucei in G. palpalis. Kleine states, that as Nagana was not present in the Kirugo region, some sheep and a mule, which had been naturally infected by the bites of $G$. morsitans, were brought from a place seven days' march away; the infected animals were kept apart from the rest. Specimens of G. palpalis caught on the Mori river were fed for three days on a mule and two sheep infected with Nagana, and from the fourth day onwards they were fed daily on a fresh healthy animal.

From the 18th to the 24th day the flies fed on the same sheep (No. 30), and from the 25th to the 39th on the same ox (No. 2). The blood of the experimental animals was examined with negative results. On the 12th day after the flies were fed on ox No. 2 a preparation of its blood was examined and numerous trypanosomes were found; as a result of this discovery sheep No. 30 was examined and in its blood many parasites 
were found. All the other animals remained healthy. Kleine remarks that from these experiments it is seen that flies, which for many days after the ingestion of $T$. brucei were not infective, afterwards became so, infecting first a sheep and then an ox. Presuming that Kleine's healthy animals were rigidly excluded from the bites of tsetse flies other than those he used, and that he was dealing with $T$. brucei throughout his experiments, it is clear that they are exactly similar to Bruce's experiment No. 225 (see Appendix for confirmation of Kleine's work by Bruce and his co-workers).

On the 4 th day 50 flies fed on sheep No. 3.
$" \quad 5$ th

G. palpalis is therefore able to transmit $T$. brucei twelve days after feeding on an infected animal. According to Minchin and Kleine this would show that during this interval $T$. brucei had undergone a developmental cycle in the alimentary tract of the fly and that the infection is of the cyclical type.

Kleine has however made no observations on such a developmental cycle in $G$. palpalis. It would be important in these experiments to ascertain whether there were any unchanged T. brucei in the alimentary tracts of the flies; Bruce has noted that T. brucei remains alive for five days in the alimentary tract of $G$. morsitans and its vitality appears to depend on the quantity of blood in the stomach of the fly. Kleine's flies were fed daily so that the parasites would here have had ample nourishment to keep them alive. This can however only be settled by further observations, but it must be remembered that $G$. palpalis itself is naturally infected with two Crithidia-C. grayi and C. tullochi. According to Stuhlmann and Minchin T. brucei undergoes a true develop- 
mental cycle in $G$. fusca. Are we then to understand that this trypanosome undergoes its evolutionary cycle in both these flies? We think this is most improbable.

Cazalbou (1906) succeeded in infecting two dogs with $T$. pecaudi(?) by the bites of freshly caught G. palpalis; he also infected a cat with some of the same flies which had been starved three and a half days. He however does not record any observations to show what changes the parasites underwent in the flies during this period.

Bouet (1907) fed $G$. palpalis on dogs infected with T. dimorphon, and twenty-four hours later the fly was fed on a healthy puppy which became infected fifteen days later. Here again there is no evidence to show that $T$. dimorphon passed through a developmental cycle in the fly. Roubaud (1907) has also carried out some transmission experiments with wild G. palpalis and $T$. dimorphon. In one experiment he found that when the infected fly was merely allowed to bury its proboscis in the tissues of the uninfected animal and not to suck its blood no infection took place. When four G. palpalis were fed on a guinea-pig twentyfour hours after having sucked the blood of an infected white mouse, the guinea-pig became infected. In this experiment Roubaud believes the trypanosomes were regurgitated from the stomachs of the flies.

The discovery that certain tsetse flies are capable of transmitting the parasite of Nagana soon led to similar experiments on T. gambiense being carried out with these insects. Bruce, Nabarro and Greig (1903) have recorded a number of interesting observations in this connection. Tsetse flies ( $G$. palpalis), which had first sucked the blood of a sleeping sickness patient, were fed eight hours later on a monkey; after 530 flies were fed during nine weeks the monkey became infected. A similar positive result was obtained with 509 flies. Nabarro and Greig (1905) have carried out similar experiments with T. gambiense; so also have Minchin, Gray and Tulloch (1906). Greig and Gray (1905) also tried to infect a monkey by using freshly caught tsetse flies; in one experiment 980 flies were fed for six and a balf weeks before an infection was produced, while in another experiment 2299 flies were fed for eleven weeks on a monkey without infecting it. Dutton, Todd and Hannington (1907) also carried out a long series of feeding experiments with tsetse flies and T.gambiense; they however doubt whether their results are of much importance as their animals were only partially protected from the chance bites of insects.

It is quite evident from a perusal of all these records of transmission experiments that it is impossible to draw any exact conclusions, as they 
have been carried out under such imperfect and varied conditions; for instance it is not certain in each case whether T. gambiense was the trypanosome under observation. Bagshawe (1909) has recently summarised the objections which apply to some or all of these experiments; we cannot do better than quote his remarks :

"(1) All were carried out with wild flies, and similar experiments at the same time and the same place showed that a certain number of such flies were infective when brought to the laboratory.

(2) The flies were in most cases fed on a healthy animal before being placed on the infected one with a view to their purging themselves of any trypanosomes they contained. But there is reason to suppose that such feeding might not have the effect desired; as Minchin points out, in Bruce's fresh fly experiments the flies were caught on healthy animals which it must be assumed they bit, and yet infection of the healthy experimental animal resulted.

(3) There is evidence that fresh flies retain the infection for more than a few hours. Cazalbou infected a cat with $T$. dimorphon after the flies had been starved for three and a half days.

(4) In some of the experiments attempts to transmit by fresh fiies and by flies supposed to be infected in the laboratory were being carried on at one and the same time; this has been already pointed out."

There is however no doubt whatever that $G$. palpalis is capable of transmitting $T$. gambiense to man and it appears to be able to do so up to 22 days after it has sucked in the parasite. T. brucei also lives in the alimentary tract of G. palpalis and produces an infection after at least twelve days; in $G$. morsitans and $G$. pallidipes it can probably live longer than five days.

\section{Schaudinn's work on the Haematozoa of the little owl.}

We would hesitate to criticise Schaudinn's (1904) memorable work, but, owing to the fact that it is again inserted in an authoritative textbook, we feel bound to do so. In criticising it however we do not wish to throw any discredit on Schaudinn's work, we have the greatest admiration for it; it is not so much Schaudinn's mistakes we wish to draw attention to, but rather to emphasize the fact that too great weight has been attached to his conclusions. After all, Schaudinn's paper on the parasites of Athene noctua was only a preliminary report, and we feel sure that had he been spared he would have considerably modified 
his views. We are told in a footnote by Woodcock (p. 239) that he has recently been able, after an arduous investigation on the Haematozoa of birds, to obtain the first definite evidence in support of Schaudinn's views. We shall criticise his recent findings later on.

It will be remembered that Schaudinn, after feeding Culex pipiens on the blood of the owl (Athene noctua) infected with Halteridium danilewskyi, claimed to have discovered the development of the intracellular parasites of the owl in the stomach of the mosquito. The Halteridium macrogamete, after being fertilised by the microgamete in the stomach of the mosquito, developed into an ookinete which became either a male, female or neutral trypanosome. These trypanosomes were then found in masses at times near the oesophageal end or at the junction of the ileum and colon. Schaudinn described complicated migrations of the parasites in the body of the mosquito, the parasites eventually developing into forms which were prepared to pass into the blood of an owl when this insect next fed.

Woodcock notes that the main criticism on Schaudinn's work is based on the probability of his dealing with at least four blood parasites : two free parasites, a trypanosome and a spirochaete (Töpfer) and two intracellular ones, Halteridium and Leucocytozoon. Woodcock however entirely omits from this list Herpetomonas culicis, Crithidia fasciculata and Spirochaeta culicis, merely mentioning them later on. We consider these are the most important parasites in connection with Schaudinn's work, and we believe that the other four blood parasites have played a small part in Schaudinn's complicated life cycles of Halteridium and Leucocytozoon. Schaudinn did not refer to his having excluded Herpetomonas culicis, Crithidia fasciculata or Spirochaeta culicis from his mosquitoes. We have shown that Culicines obtain the parasites $H$. culicis through the larva, so that in order to exclude this flagellate it is not only necessary to breed mosquitoes, but to be particularly careful in transferring the egg-rafts into water, where there is no chance of the larvae ingesting cysts passed out in the excreta of other mosquitoes. Schaudinn's mosquitoes were obtained at large at Rovigno, and we do not know whether they were caught as adults or hatched from larvae. It is not known at present how Crithidia fasciculata is transmitted from one insect to another; there is al ways the possibility that these particular flagellates may be transmitted hereditarily, and if this proves to be the case, the larvae would have to be bred from eggs laid by uninfected insects. Spirochaeta culicis, which we have recently found in the alimentary tract of adult Culex pipiens in 
Cambridge, is probably also acquired by the larvae; in Madras we have seen these spirochaetes in great numbers in the alimentary tracts of the larvae of Culicines.

Bearing the above facts in mind, it is in the highest degree probable that Schaudinn's mosquitoes were infected with one or other of the flagellates we have referred to above, and, in addition, we can find nothing in his paper to show that he excluded Spirochaeta culicis.

Schaudinn found masses of flagellates rolled up in bundles and collected in various parts of the alimentary tract of Culex pipiens. Anyone who has studied these flagellates of mosquitoes knows that they are similarly found in bundles in different parts of the digestive tracts of the insects. Then again certain of Schaudinn's figures clearly depict the non-flagellate stage of Herpetomonas, and others, stages in the development of a Crithidia. Apart therefore from the possibility of his mosquitoes containing the trypanosome, spirochaete, halteridium and leucocytozoon of the owl, we believe the gravest source of error in Schaudinn's experiments lies in the fact that the insects may have also contained two flagellates and a spirochaete. Assuming then that his mosquitoes may have harboured no less than seven parasites, we are at a loss to understand how any investigator, even with Schaudinn's great technical skill and phenomenal powers of interpretation, could possibly follow any one of the parasites through a complicated developmental cycle; we know from experience that the resulting confusion would be exceedingly great.

It is generally stated (see Mesnil, Bull. Inst. Past. v. 3, 1905, pp. 363-367) that Schaudinn actually saw a Halteridium ookinete become a trypanosome presumably in the blood from the mosquito's stomach, and that the melanin granules helped to trace the stages in the evolution. With regard to this statement, we would like to point out that we have seen a leech Crithidia in its pre-flagellate stage containing melanin-like granules, and that if such a cell be studied, apart from its flagellate stage, it may quite well be mistaken for an intracellular pigment-containing parasite. It should therefore be borne in mind that these flagellates of invertebrates may contain pigment-like granules. Could it be possible Schaudinn was dealing with the preflagellate stage of a Crithidia?

We have noted above that in a footnote (p. 239) Woodcock states that he has at length obtained the first definite and unmistakable evidence in favour of one of Schaudinn's conclusions. As a result of his observations on a Halteridium of the chaffinch, he has no doubt that in 
certain phases it becomes a little trypanosome, and in a recent paper he (1909) describes these observations. On examining the peripheral blood, heart blood, and smears of most of the organs of a chaffinch, between 1 and $3 \mathrm{a} . \mathrm{m}$., they were found to be heavily infected with Halteridium, and less so with trypanosomes. Woodcock states that he was able to recognise three types of the Halteridium, male, female and indifferent; the latter being distinguished from the female type by its much lighter staining cytoplasm, and from the male type by a more compact and denser nucleus. He was not able to find any evidences of schizogony in the red corpuscles. Many of the Halteridia exhibited nuclear dimorphism; the nuclear elements separating into two constituents, a large body staining red with Romanowsky's stain, and a smaller structure, much denser, and staining darkly; the larger body Woodcock regards as the trophonucleus and the smaller as the kinetonucleus.

Actual passage from the halteridium stage to the trypanosome form could not be demonstrated with certainty, and Woodcock says, "They appear to be few and far between." He thinks this is due to the fact that there were very few trypanosomes in the blood of the chaffinch. In a smear of the heart blood he however found a body, which he thinks is an intermediate stage between the two parasites. This structure Woodcock considers is of the indifferent type, the two nuclei being in close contact. A delicate thread or line, which stained bright red, could be seen passing from a short transverse deep-staining band down part of the length of the body of the parasite, terminating in a definite granule. Woodcock thinks this thread represents the central spindle, described by Schaudinn, and which later becomes a flagellum. In a footnote Woodcock says he has found two or three of these cells. We must confess that the evidence brought forward by Woodcock in support of his view of this intermediate stage is exceedingly slender. It is not even clear that this parasite represents what was once a living halteridium, even in spite of the fact that the blood smear was made at once. We can find no proof whatever that this parasite is of the indifferent type, and that the chromatic mass represents the nucleus and blepharoplast in close contact. It is an unjustifiable assumption to say that the doubtful pink-staining strand represents a "central spindle." Surely Dr Woodcock cannot expect his readers to accept these statements without more rigid proofs ${ }^{1}$.

In the bone marrow of a chaffinch he found small trypanosomes; he considers they have not arisen as the result of the division of larger

I In this connection see Mezincescu's (1909) recent work on Halteridium. 
forms found in the peripheral blood, but have probably developed from halteridia. It is quite a well-known fact that small trypanosomes may be frequently found in the bone marrow of birds, and we think it most probable that these small forms may develop into the larger ones Woodcock figures. Woodcock believes that the great difference in the number of trypanosomes, as compared with the halteridia, is largely reduced when the sexual forms of the intracellular parasites are omitted. As a result of his observations, Woodcock concludes that "Halteridium is probably a stage in the life history of a trypanosome which has advanced a step further and become adapted also to the red blood corpuscles." It should be noted that Woodcock's results appear to be based on the study of stained films of the peripheral blood, heart blood and organs of a single chaffinch. We are not told whether the parasites were studied in the fresh condition, or whether more than one bird was examined. We are left in doubt also as to what the halteridium of the chaffinch might do in the stomach of jts transmitting invertebrate; Woodcock's observations are based on such a small amount of material, that it is really difficult to ascertain what part of the life cycle of the parasite he was dealing with.

As far as we are aware, no other observers have noted this socalled nuclear dimorphism in halteridia in the blood of birds. We have examined many specimens of the male and female elements of the halteridium of Athene brama from the blood of the owl, but we must admit we have never seen a true blepharoplast in any of them. It is by no means proved that the structure Woodcock describes as a kinetonucleus is a true blepharoplast; as far as we can gather, this view is chiefly based on its staining reactions.

We are unable to accept Woodcock's explanation of the difficulty in finding so few examples of the intermediate stages, between the halteridium and the small trypanosomes. Surely, if this parasite is to become a trypanosome, and provided a sufficient number of birds are examined, there ought to be no difficulty in finding numerous examples of all the stages in this very important change. The single parasite, which Woodcock depicts as illustrating one of the changes towards the formation of a trypanosome, may represent anything, as it is lying free in the plasma. We can find no proof that it is destined to become a trypanosome. We therefore think it is extremely doubtful whether the trypanosome of the chaffinch has any connection with its halteridium; Woodcock's observations certainly do not support any such conclusion. We would like to see a more exhaustive study of fresh preparations of a large number of 
birds, as well as the development in an invertebrate. Woodcock does not appear to have touched on this side of the question; after all, this is where Schaudinn studied halteridium. If the difficulties in this country are too great, would it not have been better to have investigated this problem at Rovigno?

We do not wish to discourage Woodcock in his endeavours to confirm Schaudinn's conclusions, but we must say this last piece of work is most unconvincing; it is to say the least of it premature. Schaudinn's work on Halteridium therefore, in our opinion, remains as yet unconfirmed. It has certainly had a far-reaching effect, and we would now like to see the problem investigated by an international commission, carrying on its work at Rovigno.

In the seventh section Woodcock deals shortly with insect flagellates and their bearing on the evolution and phylogeny of trypanosomes. Léger's (1902) definition of the genus Crithidia is again introduced, as well as his work on certain Herpetomonads. We have shown that this definition of the genus Crithidia is inaccurate, as it is based on the structure of the immature stages of Crithidia fasciculata ; many Herpetomonads have a very similar appearance. Woodcock's description of these important flagellates is extremely inadequate and out of date; the two genera are throughout confused, as they are in Léger's original papers. Such a statement, as the following, will show that Woodcock's knowledge of these parasites is mainly second hand: "These forms (Herpetomonas) are mostly parasitic in invertebrates which do not suck blood." We know of at least two which are parasitic in blood-sucking insects, Herpetomonads of Culicines and Stomoxys.

Woodcock next goes on to discuss the relation between these flagellates and the trypanosomes of vertebrates. It will be remembered that Léger (1902) expressed the opinion that the Crithidia of mosquitces was most probably but a stage in the development of a Haemoflagellate, and that many more of these flagellates may eventually prove to ba connected with blood parasites. Novy has however expressed the opinion that these insect flagellates are distinct from the blood trypanosomes. Ross (1906) has pointed out that he found the Herpetomonas of Culicines in the insects before they had fed on blood. We (1907) have recently been able to confirm these old observations of Ross, and have further pointed out that the larvae acquire the infection by ingesting cysts of the parasites passed out in the excreta of the adult insects.

In summing up these opposing views, Woodcock attaches the utmost weight to the flagellates of the tsetse flies, which Minchin and others 
regard as stages in the development of vertebrate trypanosomes. We have shown above that the proof of this is wanting, and that there is also no proof to support the view that certain piscine trypanosomes undergo their development in the alimentary tracts of leeches. In all the instances we have quoted above, natural flagellates of the various sanguivora have not been excluded. We have no hesitation in saying that Herpetomonas culicis and Crithidia fasciculata, studied by Novy and his collaborators (1907), are in no way connected with an avian trypanosome. The American observers only studied the fiagellate stages of the parasites in the mosquitoes and in test tubes. Had they however investigated their life cycles, as we have, we have no doubt that they would have found conclusive evidence to show that these flagellates are entirely limited to their insect hosts. We therefore cannot agree with Woodcock that any of these insect flagellates are connected with avian trypanosomes. It is quite premature to say that some of them may have developed a trypanosomal condition as an adaptation to the food of these sanguivorous insects, without being able to live in the blood of the vertebrate. The study of these flagellates in test tubes, and more especially partial descriptions of their life cycles, have largely contributed to the many erroneous views regarding their structure and relations.

In his first article (1906) on the Haemoflagellates Woodcock expressed the opinion that trypanosomes had originated from an ancestor parasitic in invertebrates. He however now believes that the trypanosomes which have the vertebrate for their primary host are Heteromastigine forms, i.e. are derived from a bi-flagellate Bodo-like type; those parasitic in invertebrates he believes have originated from a Monadine ancestor. Woodcock states that in bringing forward this view he has been mainly influenced by the intestinal Trypanoplasmata, and by Minchin's observations on Crithidia grayi. As so little is known of the intestinal trypanoplasmata, we think it is dangerous to draw important conclusions from our present knowledge of these forms. Are they true trypanoplasmata? We do not know this for certain. We have pointed out above that Minchin's hypothesis, regarding the life cycle of the flagellate of $G$. palpalis, is based on an incomplete study of its life history, as well as that of the tsetse fly, and that it is most improbable; in our opinion $C$. grayi is a true parasite of $G$. palpalis. Woodcock further thinks sufficient weight has not been attached to the fact that the majority of invertebrates, which harbour trypanosomes (according to our view crithidia), are blood-sucking insects. A large number of Rhynchota and flies which are not blood-suckers harbour typical Crithidia. 
How then can these invertebrates be second or intermediate hosts of various vertebrate flagellates? As far as we know there is no proof to show that the common house fly has descended from a blood-sucking ancestor, and that $H$. muscae domesticae and the new flagellate we have found in its malpighian tubes have been derived from haemal forms. The same may be said of Sarcophaga and its flagellates, Lucilia and a host of others.

Woodcock in his remarks on the diphyletic origin of the trypanosomes refers the reader to his original article (1906, pp. 270-278), where he discusses the whole question at length; we shall now examine his arguments in detail. Before however doing so, it is necessary to understand our position with regard to this difficult subject.

We consider Woodcock's Trypanomorpha noctuae (Schaudinn's T. noctuae) is nothing more than Crithidia fasciculata and possibly $H$. culicis, and that the Crithidia and Herpetomonas of blood-sucking arthropods and leeches are true parasites of these invertebrates, and therefore do not represent part of the life cycles of vertebrate trypanosomes. In support of his views Woodcock lays particular stress on certain biological and morphological conditions. Under the first beading he says that the sensory extremity of a Haemoflagellate is its anterior end, and that $T$. ziemanni, in its resting stage, attaches itself and penetrates a leucocyte by its non-flagellate extremity. The parasite referred to here is Haemamoeba ziemanni, Laveran, which Schaudinn regards as being but the stage of a Spirochaeta. We believe that Schaudinn confused this intracellular parasite of the owl with the flagellates of Culex pipiens, and more particularly with Spirochaeta culicis. In any case we do not understand what connection this Haemamoeba has with a Haemoflagellate, and it is by no means proved that it is a spirochaete. Herpetomonas and Crithidia we know always attach themselves to the intestinal epithelium of their hosts by their flagella; on the contrary it is not known by what means the trypanosomes and trypanoplasmes attach themselves. It would be important to know how Crithidia penetrate the eggs of their hosts and how Endotrypanum schaudinni penetrates the red corpuscles of Cholaepus didactylus. Granting any of the points on the methods of attachment brought forward by Woodcock, it is however hardly justifiable to draw any far-reaching conclusions from a few doubtful observations.

With regard to the process known as agglomeration, we have pointed out above (p. 97) that a clear distinction should be drawn between the true rosette and a mere agglomeration of adult flagellates; the former is 
a developmental process, while the latter is brought about by certain unknown changes in the medium in which the parasites live. Herpetomonas and Crithidia, as far as we have studied them in the intestinal juices of insects, agglomerate in their adult stages by their flagellar ends; and it is a physiological process. Adult Trypanosomes however collect together by their aflagellar ends and this change takes place under unfavourable conditions; it is doubtful whether it naturally occurs in the blood of vertebrates. It is therefore most probably a pathological process. In the case of $T$. lewisi it is well seen when the serum of a rat, inoculated two or three times with this trypanosome, is added to blood rich in parasites. Laveran and Mesnil consider this process is brought about by a specific agglomerin. The agglomeration of Herpetomonas and Crithidia in the intestinal fluids of insects is therefore by no means comparable with the agglomeration of vertebrate trypanosomes under unfavourable conditions. Can we then attach any great importance as Woodcock does to the different methods of agglomeration?

The process of conjugation is hardly worth mentioning as there is not a single instance in which it has been described from Haemoflagellates; the so-called examples of conjugation, T. lewisi and T. brucei (Prowazek), represent something quite distinct, for example in the case of $T$. lewisi from the louse they are undoubtedly Crithidia dividing unequally.

The majority of trypanosomes we have studied travel forwards by their Hagellar ends, except perhaps the very stout forms of T. rotatorium. It should however be remembered that we are only able to observe the movements of these flagellates under artificial conditions; the very best instruments we can employ can hardly replace the conditions in the blood of the host. Are we to understand then that the slow crawling movements of certain trypanosomes on slides, when they move by their aflagellar ends, are their normal methods of locomotion? We are not sure of this and we would hesitate to attach any great importance to it.

Considering then more closely all the biological data brought forward by Woodcock to support the view, that the non-flagellate end of a trypanosome is the sensitive end, we find that the majority of his arguments are open to grave criticism, and the only point we might concede him is the possible progression of some trypanosomes by their aflagellar ends under unfavourable conditions.

Under the heading "morphology" Woodcock lays stress on the cellvacuole situate in the aflagellar end of certain trypanosomes, T. lewisi and $T$.gambiense. Are we to consider this a normal cell constituent, and does it represent the (original) contractile vacuole of an ancestral 
Haemoflagellate? Is it homologous with a similar structure in Trypanoplasma and Herpetomonas? We would like to ask Woodcock whether he has any definite evidence to support his contentions? Surely it is gratuitous assumption to say what he does about it, and to attach such importance to it. We would prefer to leave it alone at present, till we know something more about it. The same may be said regarding the chromidia of trypanosomes and allied flagellates. We do not know for certain that their position in a parasite is of much importance.

All the data, both biological and morphological, brought forward by Woodcock, appear to us, after detailed examination, to be of very little importance, and some of his assertions are certainly incorrect; we therefore consider that they do not add any weighty support to his view on the diphyletic origin of the trypanosomes.

\section{Brumpt and Léger's hypotheses.}

It will be convenient here to consider some of the other hypotheses on the origin of the Haemolagellates of vertebrates. Brumpt (1908) in a recent paper has summarised his views on the origin of these parasites. He first refers to Chatton and Alilaire's (1908) recent discovery of a trypanosome from the malpighian tubes of Drosophila confusa. We are not sure that this flagellate is a true trypanosome, for the reason that both Herpetomonas and Crithidia may exhibit an appearance very like this parasite (see Donovan, 1909). We (1909) have recently figured this stage in a Crithidia, C. ctenophthalmi, from the alimentary tract of Ctenophthalmus agyrtes; in this particular stage (post-flagellate) this flagellate is not at all unlike some trypanosomes. We have seen Herpetomonads exhibit a somewhat similar appearance, and Roubaud (1908) has figured this stage in two typical Herpetomonads, $H$. mirabilis and $H$. mesnili. We would like to point out here that this trypanosomelike phase is seen in the post-flagellate stages of these flagellates, and we believe the migration of the blepharoplast to the posterior end of the cell is due to the degeneration of the root of the flagellum and the subsequent liberation of the blepharoplast. We note Roubaud (1908), found these stages of $H$. mesnili in the posterior intestine of a species of Lucilia; he has however made no attempt to trace out the life cycle of the parasite. At present therefore we cannot accept the statement made by Brumpt that Chatton and Alilaire's recent discovery confirms his hypothesis on the origin of the Haemoflagellates. Brumpt says, "Ces Flagellés seraient des vulgaires parasites intestinaux d'invertebrés 
inoculés fortuitement par ces derniers aux vertébrés, au milieu sanguin desquels ils ont pu s'adapter." Léger (1902) has also advanced a similar hypothesis, that the Crithidia and Herpetomonas of biting insects are perhaps but stages in the evolutionary cycle of vertebrate trypanosomes.

Brumpt bases his hypothesis on what he considers to be the development of certain fish trypanosomes in leeches; we have fully criticised his researches on the evolution of these trypanosomes in leeches, and have clearly shown, that as he has not rigidly excluded a natural Crithidia of the leeches, his work on the fish trypanosomes cannot be accepted as being accurate.

Bruınpt goes on to say " $A$ un point de vue général, mes études sur l'évolution des Flagellés des Poissons montrent que les cultures artificielles des Trypanosomes sur gélose au sang représentent certainement le cycle évolutif dans l'hôte intermédiaire à sang froid (Glossines, Puces, Taons, etc.); elles expliquent également pourquoi ces cultures réussissent mieux $\grave{a}$ froid qu'à chaud."

This statement is wholly inaccurate, as there is no evidence to show that the artificial multiplication of trypanosomes on blood agar "certainly represents" the evolutionary cycle in a cold-blooded intermediate host. It has not yet been proved that certain vertebrate trypanosomes of Africa, T. brucei and T. gambiense, undergo any evolutionary changes in tsetse flies (see p. 103 and Appendix); T. lewisi certainly does not undergo the same multiplicative changes in fleas as it does in blood agar; we have ourselves investigated this question. There is also no evidence to show that a vertebrate trypanosome undergoes a developmental cycle in horse flies; we have recently made a complete study of a Crithidia in a Tabanid, and we know it has no connection with any trypanosome, but is a true parasite of the fly. Brumpt further states, "Actuellement, je suis bien convaincu qu'elles (la mouche tsétsé) sont des hôtes intermédiaires au même titre que les Hirudinées." Here again we have shown that the tsetse flies cannot be considered as true intermediate hosts of pathogenic trypanosomes, for the simple reason that there is no evidence to show that these trypanosomes undergo any development in the flies; the so-called developmental forms are certainly natural Crithidia of the flies. Again there is no proof that the trypanosomes after undergoing a developmental cycle in the flies pass to the proboscis and are then inoculated into a vertebrate, when the fly sucks its blood; the same may be said for the flagellates of leeches. All the evidence, at present to hand, appears clearly to show that the pathogenic trypanosomes of 
Africa are transmitted mechanically by the tsetse flies, and this probably also holds good for leeches and the trypanosomes they transmit.

We have fully criticised Brumpt's work on the development of T. granulosum in Hemiclepsis marginata and pointed out that, as he failed to exclude a natural flagellate of the leech, his work cannot be accepted as being altogether correct. From our present knowledge we are justified in saying, that the trypanosomes of vertebrates do not undergo any developmental (sexual) cycle in invertebrates; how then can they be considered as representing primitive intestinal or enterocoelomic parasites of invertebrates which have become partially or secondarily adapted to the blood of a vertebrate?

Brumpt concludes his paper with the following remarkable statement: "Enfin, en juillet 1907, je démontre la transmission héréditaire normale de Trypanosomes et de Trypanoplasmes chez les Sangsues, tout à fait en dehors du parasitisme d'un hôte vertélbré. Ce qui démontre d'une façon définitive que la maladie sanguine du vertébré n'est qu'un accident, que l'adaptation d'un parasite intestinal banal d'invertébré." In our opinion Brumpt is here obviously confusing the natural Crithidia of leeches, which are transmitted hereditarily, with the trypanosomes they may ingest. We know of no definite experiments showing that trypanosomes of vertebrates may be transmitted through a sanguivorous invertebrate to its progeny. Brumpt (1907) has recorded certain observations on the hereditary transmission of what he considers to be trypanosomes and trypanoplasmes of vertebrates in leeches. The first experiments described are those with Helobdella algira which transmits $T$. inopinatum. One leech infected with $T$. inopinatum gave birth to a number of embryos, two out of every ten of which were infected. Four of these embryos were allowed to arrive at maturity, and two of them laid eggs, which were not infected, while the remaining two gave birth to infected embryos, one showing five out of ten and the other nine out of ten with parasites. The trypanosomes were generally found in the sheath of the proboscis, also in the caeca, but never in the intestine. The parent leech referred to above was presumably infected with flagellates, but we would like to know on what grounds Brumpt regards these as being developmental forms of $T$. inopinatum? No figures of these parasites are published, and no mention is made of the leech being infected or not with a Crithidia; Brumpt has apparently overlooked such a parasite. Further, no experiments are recorded to demonstrate whether or not the infected embryos of the first generation are capable of transmitting T. inopinatum to healthy frogs; such experiments are 
necessary. A certain percentage of the second generation of leeches were also infected with flagellates, and these again were regarded as stages of $T$. inopinatum, yet we can find no proof that this is actually the case. In a species of Glossiphonia we found that about $80-90 \%$ of the embryos from an infected parent had Crithidia; these flagellates were in no way connected with a frog trypanosome, nor was it possible to transmit them to healthy frogs. We therefore believe that Brumpt has fallen into the error of describing a natural Crithidia of $H$. algira which is transmitted hereditarily. We can well understand, that as a certain percentage of embryos of this leech are not infected, all their progeny would remain clean, and that although they may be fed ever so many times on infected frogs, they will themselves never become infected; in our opinion this does not indicate that the leech is refractory, but that $T$. inopinatum does not undergo any developmental changes in the leech. In one experiment forty uninfected leeches were fed on infected frogs for ten days, and then isolated for seven days, after which they were placed on a clean frog which later became infected. This experiment in our opinion only shows that T. inopinatum may be transmitted after at least seven days ${ }^{1}$; we would like to know if there were any unchanged trypanosomes (T. inopinatum) in the sheath of the proboscis of the leeches.

In the case of Helobdella stagnalis Brumpt found trypanoplasmata abundant in the proboscis of specimens of this leech; a large percentage of the embryos of an infected parent were themselves infected. We are left in doubt as to the origin of this trypanoplasm, and would like to know whether it is a true Trypanoplasma or a Crithidia of the leech transmitted hereditarily. Brumpt has not published any figures of the flagellate.

Brumpt has examined some hundreds of embryos of Hemiclepsis marginata descended from adults infected with various species of trypanosomes and trypanoplasmes of fresh water fish, but he was never able to demonstrate hereditary transmission. Similar results were obtained with $P$ iscicola geometra. Is it possible that the flagellates of these two leeches are transmitted in some other way? In every instance Brumpt has failed to exclude a natural flagellate of the leeches he was dealing with; surely this is a grave source of error. Now that it is known that these flagellates commonly occur in leeches, it is first necessary to exclude them before it is possible to trace the development of any other parasite which may be ingested by these invertebrates.

1 This experiment at once recalls Kleine (1909) and Bruce's recent work. 
We cannot then agree with Brumpt that the haemoflagellates of vertebrates are common intestinal parasites of invertebrates.

We have noted above that Léger has advanced much the same idea, and he believes that the flagellates of vertebrates were once true insect forms which have gradually become adapted to the blood ingested by invertebrates, and have in process of time become transferred to vertebrates. This is a very simple and convenient hypothesis, but unfortunately there is at present no proof in support of it; we do not know of a single vertebrate trypanosome which passes its sexual cycle in an invertebrate, that is, its life cycle does not consist of an alternating blood and gut parasitism.

Where then have the trypanosomes come from? In studying the methods of development of $T$. lewisi and $T$. rotatorium in their vertebrate hosts, it is clear that they exhibit changes very similar to Herpetomonas and Crithidia; according to Salvin-Moore and Breinl T. gambiense and T. equiperdum also exhibit such stages. These facts suggest that the ancestor of the present true trypanosome of the blood of vertebrates was a crithidia-like flagellate. The interesting question is, was this crithidia-like ancestor a blood parasite or an intestinal form? At present it is impossible to answer this question, as $\mathbf{n}$ o true trypanosome has been found in the intestinal tract of a vertebrate or invertebrate. The only instance of what may be a trypanosome has been recently described by Chatton and Alilaire (1908) from the malpighian tubes of a non-biting fly Drosophila confusa. We do not consider this parasite is a true trypanosome, because the authors have not worked out its complete life cycle, and may quite well have mistaken a particular stage in its life history for a trypanosome (see p. 119). Even admitting that this parasite is a true trypanosome, its occurrence in the intestinal appendages of a non-biting fly is exceedingly difficult to explain.

The greatest obstacle in the way of understanding this group of blood parasites is the fact that, although they have a common morphological structure, they exhibit great variation in their length, breadth and other minor details, and most important of all we know practically nothing regarding their life cycles. An important advance however in the study of these parasites has recently been made by Salvin-Moore and Breinl ; these authors have brought forward observations on certain trypanosomes, which suggest that they pass the most important part of their life histories in the blood and organs of their vertebrate host. Let us take T'. lewisi as an example, this flagellate (see Nuttall, 1909) can be readily transmitted to white rats by means 
of fleas ( $C$. fasciatus and $C$. agyrtes) by placing on them a number of these insects, which have recently been removed from an infected wild rat. Now we know this trypanosome does not undergo any developmental changes in the intestinal tracts of the two fleas, and that the parasites are most probably transmitted mechanically after finding their way to the proboscides of the insects.

In from six to seven days after the fleas have been placed on a rat, if the experiment is going to prove successful, the blood of the rat will be found to contain large numbers of young flagellates. Some of these are quite round and have short or long flagella, and are exactly like certain Crithidia, especially those undergoing division (see Laveran and Mesnil's (1904) excellent figures illustrating these changes in $T$. lewisi). The multiplication rosette of T. lewisi is also very suggestive of a Crithidia (see figures 6, 7 and 8 Laveran and Mesnil (1904)); the flagella of the developing parasites are directed externally and each flagellum at an early stage is attached to the body of the parasite (compare the above figures with those of C. gerridis). T. rotatorium also exhibits similar appearances in its developmental stages in the blood of frogs. We do not wish bere to include the cultural forms of a number of trypanosomes, as we do not consider they represent the true developmental cycles of the parasites, but are rather pseudo-developmental forms; certain trypanosomes readily exhibit these changes, when they are cultivated on artificial media, such as blood agar; why they do so we cannot explain. We think then these facts suggest that the two trypanosomes (T. lewisi and T. rotatorium) have descended from crithidia-like ancestors. So far the majority of Crithidia have only been found in the intestinal tracts and appendages of blood-sucking and non-blood-sucking arthropods and leeches, but quite recently Wenyon (1909) has recorded a flagellate from the blood of a snake (Erythrolamprus aesculapii), which is very like some Crithidia; and again the flagellate which Brimont has recently found in the red blood corpuscles of Cholaepus didactylus may quite well prove to be but a stage of a Crithidia. We may then, in the case of these parasites, be dealing with two haemal forms, which perhaps exhibit the peculiarities of ancestral haemoflagellates. The fact that one of these parasites penetrates the red blood corpuscles of a vertebrate, suggests that it may probably be the more primitive of the two. We would then suggest that the ancestors of the present trypanosomes may probably have been intraglobular crithidia-like forms. We will leave this question at this point, as it is unwise with our present limited 
knowledge to speculate further. When we know more of the life histories of the trypanosomes and especially of such forms as have recently been described from snakes and from the two-toed sloth, we may be in a position to formulate a more definite hypothesis regarding the phylogeny of the Haemoflagellates. Before leaving this subject however we wish to emphasize the fact that the present Herpetomonas, Crithidia and Trypanosoma are distinct forms, and that as far as we know one does not become converted into the other. Because a trypanosome may exhibit certain stages in its development like a Crithidia, we are not justified in calling it a true Crithidia and vice versa; exactly the same may be said regarding Herpetomonas and Trypanosoma.

The eighth section of Woodcock's article is devoted to the systematic consideration of the Haemoflagellates; here we find that he divides the sub-order Monodina into the single family Trypanomorphidae. We have shown above that the genus Trypanomorpha is almost certainly Crithidia fasciculata of Léger, so that this new genus can hardly be retained. Woodcock divides the sub-order Heteromastigina into one family in which he places the genera Trypanoplasma, Trypanophis and Trypanosoma; we are left in doubt as to where the important genera Herpetomonas and Crithidia come into this classification as no mention is made of them here.

We have pointed out above that the orientation of the body, and the biological features associated therewith, which Woodcock has used as important diagnostic characters in support of his classification, are very faulty, and that therefore this grouping of these flagellates is open to criticism. In the present, state of our knowledge, it would bave been wiser to have refrained from making new families, and genera, and to have been contented with a much simpler and more natural classification. We would prefer to group the Haemoflagellates and allied forms as follows :

$\begin{array}{cl}\text { Class } & \text { MASTIGOPHORA. } \\ \text { Sub-class } & \text { LISSOFLAGELLATA. } \\ \text { Order } & \text { MONODIDEA. } \\ \text { Sub-order } & \text { Monodina. } \\ \text { Family } & \text { Trypanosomatidae. } \\ \text { Genus } & \text { Trypanosoma. } \\ ", & \text { Trypanoplasma. } \\ " & \text { Crithidia. } \\ " & \text { Endotrypanum. } \\ " & \text { Herpetomonas. }\end{array}$


Woodcock gives a short account of some of the more important trypanosomes, grouping them together under the heading of their various hosts. We note that such important parasites as $T$. evansi, T. equiperdum and $T$. theileri are only just mentioned; we would like to have seen these and other lethal forms described fully.

Woodcock's appendix (A) is devoted to a consideration of the Leishman-Donovan-Wright-bodies, but it does not contain anything new regarding the parasite of Kala-Azar. We fail to understand what connection Wright has with this parasite, unless it is that Woodcock regards it as identical with the parasite of Oriental Sore. We note that Woodcock considers these two parasites are closely related on the one hand with Herpetomonas, and on the other with the Piroplasmata. We need hardly say that we do not consider there is any evidence to support the view, that the parasite of Kala-Azar is in any way connected with a Piroplasma. It has yet to be proved that the Piroplasmata have a true blepharoplast analogous to that seen in Herpetomonas, Crithidia and Trypanosoma.

Through the kindness of Professor Nuttall we have had the opportunity of examining Breinl's (1908) recently described flagellate stages of $P$. canis, and we have no hesitation in saying, that they are quite unlike the characteristic flagellates of Herpetomonas; indeed we are doubtful whether they represent true flagellates. With regard to Kossel and Weber's observations (see Schaudinn, 1904) on the flagellates found in smears of the intestinal contents of ticks, fed on cattle infected with Piroplasma, we would suggest that they were probably only flagellates of the tick, such as are known to occur in Rhipicephalus sanguineus and Haemaphysalis flava.

Professor Nuttall, who is at present investigating Theileria (Piroplasma) parva, has kindly permitted us to state, that cultural experiments with this parasite, up to 149 hours, have so far yielded negative results. We (1907) have elsewhere suggested that Miyajima's (1907) observations on cultures of $T$. parva of Japanese cattle are probably erroneous, in spite of the fact that he carefully guarded against the possibility of his cultures being infected with trypanosomes of the cattle. Miyajima's figures of the seventy-two hour cultures show typical trypanosomes. How the diminutive $T$. parva comes to develop into these huge parasites is not explained; we would like to see this work confirmed by other observers.

We (1908) have recently described a Herpetomonas which is identical in appearance with the parasite of Kala-Azar, and further we have pointed out that these herpetomonads exhibit the same stages in their 
life histories as the human parasite does in man, and in the bed bug Cimex rotundatus. We therefore see no reason why this flagellate should be placed in a distinct genus (see also remarks in recent paper by Patton, 1909).

Woodcock makes no reference to Nicolle's (1908-1909) recent work on Herpetomonas infantum, the causal agent of Algerian herpetomoniasis. Nicolle has studied ten cases of this disease in Tunis, the characteristic symptoms of which are, irregular fever, anaemia, general emaciation, hypertrophy of the spleen and oedema. All the cases occurred in young children from several months to five years old; Indian herpetomoniasis on the other hand is common both in children and adults of all ages. Nicolle has only been able to find the parasite once in the peripheral blood of a patient; this contrasts markedly with Donovan's observations in Madras, where Kala-Azar is diagnosed solely by examinations of the peripheral blood. Nicolle (1908-1909) has succeeded in reproducing the Algerian disease in dogs and monkeys, by inoculating them with infected tissue; he has also cultivated the parasite on blood agar, not only from the spleens of diseased children, but also from naturally infected dogs. He however failed to reproduce the disease in dogs and monkeys by inoculating them with pure cultures, and concluded that the cultural forms had probably lost their pathogenicity. Novy (1909) has however recently succeeded in infecting a dog with $H$. infantum by inoculating it with 270 tubes of blood agar cultures in 15 inoculations extended over a period of 161 days. We would like here to draw attention to a point which we think both Nicolle and Novy have overlooked. It is well known that in artificial cultures of these human parasites many of them never develop into flagellates, but some remain for many days, even months, unchanged; we have ourselves seen this in cultures of the parasite of Kala-Azar. Now Nicolle and Novy's observations show that a very large number of cultural forms (flagellates) have to be inoculated before the disease can be reproduced in dogs, whereas a small quantity of blood containing the undeveloped parasites readily produces it. Could it not then be that in Novy's cultures there were some unchanged (our pre-flagellate stage) parasites, and that by inoculating a sufficient number of these he was able to reproduce the disease? Novy however does not state whether his cultures contained unchanged forms in addition to the flagellates; we would draw his attention to this point. The reason why we suggest this, is because we have demonstrated beyond any doubt that all Herpetomonads, in order to pass from one host to another, must return to their non-flagellate (post-flagellate) stages. In the case of 
those species entirely limited to insects, this stage takes place by the parasites encysting, either in the rectums or ovaries of their hosts. We believe therefore that these human parasites, in order to be reintroduced into man, must be inoculated in their non-flagellate stages, and it is most probable that Novy was dealing with some of these unchanged forms in his cultures. This clearly explains the reason why it is necessary to inoculate such large numbers of flagellates in order to produce the disease, while a very small quantity of splenic blood containing the pre-flagellate stages of $H$. infantum readily produces the disease in dogs and monkeys.

As a result of his observations on the canine form of the disease, Nicolle claims that this animal is probably the source of the parasites which are inoculated into children through the intermediary of some blood-sucking insect. It is however by no means proved that Nicolle is dealing with a single species, the canine parasite may possibly be quite distinct from the infantile form; this can only be settled by finding out the invertebrate hosts of the parasites. With the infection in an animal like the dog, there ought to be no difficulty in carrying out feeding experiments with likely blood-sucking insects, in order to find out in which particular one the flagellate stage occurs. Similar experiments should be carried out with the human disease, and then once having found out the right insect, transmission experiments could be conducted on dogs and monkeys. So far as we are aware such experiments, as we have mentioned, have not yet been carried out.

Recently we (1908) inoculated dogs with the fresh virus of Indian herpetomoniasis with negative results, and we pointed out that so far $H$. donovani has not been found in Indian dogs; these observations confirm our view that this parasite is distinct from the Algerian form. We have shown that many herpetomonads are identical in their nonflagellate stages, and that if this stage alone is studied it is impossible to distinguish between distinct species; it is only by studying the complete life cycles of these parasites that this can be accomplished.

The parasite of Oriental Sore in its non-flagellate stage is also identical with the similar stages of the above parasites. Nicolle (1908) has succeeded in cultivating the Algerian form of Oriental Sore on blood agar and shows that it does not differ to any great extent in its cultural forms from those of $H$. infantum.

Row (1909) has recently cultivated the parasite of Delhi boil, and finds that though its method of development is very similar to that of $H$. donovani, it differs in some structural details. We have not seen 
Row's figures and are therefore unable to express a definite opinion on his results. Here again we believe it very probable that the parasite of Delhi boil may eventually prove to be quite distinct from the parasite of Algerian Oriental Sore. Unfortunately nothing is yet known as to how these parasites are transmitted from man to man; as the diseases they produce are benign they offer an excellent opportunity for this line of investigation; without doubt the solution of this problem would help to a better understanding of the methods by which the more dangerous parasites are transmitted.

Quite recently Schneider (1909) has brought forward an interesting observation, which suggests that the parasite of Persian Oriental Sore may be transmitted by the bed bug (species not named, but almost certainly C. rotundatus):

A European lady, who lived for some time at Zerguendeb, a village close to Teheran, stated that she awaked one night with the sensation of something biting her on the cheek; putting up her hand to feel what it was, she caught a bug. A little later a large sore developed on the spot where the bug had bitten her. Schneider states that in the same house there were four children, who had the sore the preceding year, and that the house was infested with bugs. Schneider however does not state that the characteristic parasite was recovered from the sores.

Laveran (1909) and others have suggested that the domestic fly is the most probable transmitter of this parasite because the sores usually occur on uncovered parts such as the face, hands and arms. This however is most improbable for the simple reason that it would be impossible for the fly to obtain the parasites, as they do not occur at the surfaces of these sores; it is well known that these parasites cannot live in the presence of septic organisms. H. tropica can only be transmitted by a blood-sucking insect which must obtain it from the peripheral blood. It is not true that bed bugs only bite covered parts of the body, for from a large experience of the habits of this insect we know that it chiefly bites uncovered parts of the body. We have visited a large number of native houses in Madras, and found that the majority of the occupants sleep on the floor, either in a room or in rows along the verandahs. The parts of their bodies that are uncovered are their legs, arms, head and neck and often the whole chest if the weather is very warm. In every house C. rotundatus will be found in large numbers in crevices in the walls, doors, chairs, beds and mats; and during the night they come out and attack the uncovered parts of the sleepers, biting chiefly round the neck, also the face, hands, feet and ankles. We have no doubt that these conditions 
hold good for other tropical countries. As a result of our experience we find bugs are rarely carried about in people's clothes except perhaps by those who are exceptionally dirty and never change their clothes, such as Tibetans and Chinese; in these cases bugs might be able to breed in the folds of their clothing. We have found that $C$. rotundatus prefers to breed and lay its eggs in places where it is likely to remain undisturbed, such as crevices in walls, doors, beds, tables and chairs. Knowing these facts then we can see no reason why the bed bug may not be a suitable transmitter of Oriental Sore.

In appendix B, Woodcock deals with the Spirochaetes, and after referring to Schaudinn's views regarding these parasites, dogmatically asserts that, "the preponderance of opinion is decidedly against these organisms belonging to the Protozoa." No references are given in support of this assertion, and we have no hesitation in saying it is inaccurate.

Woodcock makes no mention of Spirochaeta duttoni although it is a blood parasite, and together with $S$. carteri is the best known of the disease-producing Spirochaetes. Woodcock is apparently unaware of Breinl and Kinghorn's (1906) experimental study of the parasite of African Tick Fever; also Dutton and Todd's (1907) note on the morphology of the same parasite, or else he chooses to ignore these papers. The morphological and biological characters of spirochaetes, which determine their inclusion in the Protozoa, have been summarised by Nuttall (1908) in a recent paper, which Woodcock has also ignored. No reference is made to the other importantblood-inhabiting spirochaetes, such as $S$. anserina, S. theileri and $S$. marchouxi and many others. Some of these, for instance, $S$. duttoni, $S$. theileri and certain leech spirochaetes, are known to be transmitted hereditarily; these, together with other well-established facts, leave no doubt that spirochaetes are true Protozoa.

Woodcock then deals in an unsatisfactory manner with "Trypanosoma" balbianii found by Certes (1882) in the crystalline style and digestive tract of the oyster, stating that this organism "greatly resembles (in structure) a true Spirochaete." No reference is given to Fantham's (1907-08) important work on this spirochaete, and it is not a fair statement "that Perrin's (1906) whole paper thereon is most unconvincing." Woodcock is hardly in a position to make this emphatic statement, unless he has personally worked for some considerable time at these difficult parasites, and we are not aware that he has published any observations on Spirochaetes. If he had studied these parasites, we feel 
sure that he would not have stated that " $T$." balbianii more than resembles a Spirochaete, for it actually is a Spirochaete, and should now be called Spirochaeta balbianii (see Fantham, 1907-08).

Treponema pallidum, which was found by Schaudinn in syphilitic lesions, is next discussed, but in a most incomplete manner. It is obvious Woodcock has not verified his references, for he states that Krzysztalowicz and Siedlecki " in a recent memoir" (the italics are ours) have given a detailed account of this organism; the paper referred to was written in 1905 (see the Author's References to Literature, p. 273). No mention is made of Krzysztalowicz and Siedlecki's later paper (March 1908) on Treponema (Spirochaeta) pallidum, in which they state that the Spirochates should be placed in a distinct section of the Mastigophora for which they propose the name Spirilloflagellata. We do not entirely agree with the formation of such a group, but think the omission of any reference to this important paper is unfortunate.

In dealing with the Spirochaetes, we note that Woodcock does not refer to any paper published since 1906, and most of those quoted by him are not later than 1905. It is unnecessary therefore to deal any further with his dogmatic assertion that the Spirochaetes are Bacteria. We are sorry to note the entire absence of figures of Spirochaetes, and that these organisms are less satisfactorily treated here than in his (1906) earlier article on the Haemoflagellates. It is a great pity that in a memoir, which claims to be comprehensive, the Spirochaetes, which are closely allied to the Haemoflagellates, are dismissed in a little more than a page, and are then only noted from a standpoint which is biassed and out of date. Woodcock has missed a great opportunity of giving a broad yet succinct account of the Spirochaetes in this English treatise of Zoology.

In the postscript Woodcock refers to Roubaud's (1908) recent work on certain peculiar developmental forms of lethal trypanosomes in the proboscis of $G$. palpalis. We (1909) have recently criticised this work and pointed out that there is no evidence to show that the flagellates seen by Roubaud in the proboscis of G.palpalis are anything more than natural parasites of the fly. We have suggested that the various forms seen by Roubaud in this tsetse fly may quite well represent two distinct species; one of these may be $C$. grayi, and the other $C$. tullochi. Roubaud, as well as all the other observers who have studied these flagellates of tsetse flies, have failed to inoculate animals with them; surely this fact proves conclusively that these parasites have nothing whatever to do with any lethal trypanosome. 
Woodcock has compiled a very complete list of all the known hosts of the haemoflagellates and allied forms; this list ought to be of great use to subsequent observers. The flagellates of insects and leeches are confused with trypanosomes, and we note that the Crithidia we described from Gerris fossarum is wrongly called a Herpetomonas. A fairly complete list of references to the literature concludes the article; many recent important papers are however entirely omitted.

After having carefully read Woodcock's article on the Haemoflagellates we regret we are unable to recommend it to students of Tropical Medicine and Protozoology as it is already out of date and quite inadequate for their requirements ; it is too full of hypotheses and dogmatic assertions, which are based, in many instances, on erroneous observations. It is quite evident Woodcock has had very little practical experience with the majority of the parasites he describes, his facts having been collected from various sources and containing nothing original. The result is that he is not in a position to form a sound judgment on the mass of observations he has attempted to describe. Under the circumstances we consider Woodcock would have done much better had he contented himself with a detailed description of the various Haemoflagellates and the numerous insect forms, adding to this some original drawings.

Before concluding our review, we wish to indicate what we consider should be the future lines of research on these important parasites. It is now conclusively proved that certain trypanosomes, $T$. gambiense, $T$. brucei and $T$. lewisi are transmitted mechanically by insects, for instance T. gambiense by G. palpalis, T. brucei by G. morsitans, G. pallidipes and G. palpalis.

Excluding the natural flagellates of these insects, there is no evidence to show that these trypanosomes undergo a true developmental cycle in the alimentary tracts of their insect transmitters. Where then do these trypanosomes pass the important stages of their life histories? SalvinMoore and Breinl's recent observations suggest that some of these blood flagellates manifest a cyclical metamorphosis, which corresponds closely to an alternate absence and presence of the parasites in the blood of their vertebrate hosts. Latent bodies consisting of a nucleus and a vesicle surrounded by a delicate covering of cytoplasm are formed when the parasites are at their minimum in the peripheral blood. These nonflagellate stages are found in the spleen and bone-marrow, and later give rise to flagellates. During the formation of these latent bodies there is an interaction between the blepharoplast and the nucleus; does this represent a sexual phase? In the light of our knowledge that a number 
of these trypanosomes undergo no true cyclical changes in their transmitting insects, it is natural to infer that this cycle takes place in the blood and organs of their vertebrate hosts. We would therefore like to see this side of the problem carefully investigated and to know whether Salvin-Moore and Breinl are correct in their conclusions'.

We would then suggest that future research on the trypanosomes and allied forms be conducted along the following lines:

1. Careful transmission experiments should be carried out with the various blood-sucking arthropods and leeches, in order to ascertain which particular invertebrate is capable of transmitting a given trypanosome or trypanoplasm, and for how long after it has fed on infected blood.

2. Having found the right invertebrate, an exbaustive study should be made of its natural flagellates, devoting particular attention to the methods of transmission of these parasites; they may be transmitted by means of cysts or by true hereditary infection. Having acquired this knowledge, it would then be possible to exclude any natural flagellate, and to study the possible evolutionary cycle of the vertebrate trypanosome, in the digestive tract of the transmitting invertebrate.

3. Should it eventually be found that the trypanosome does not pass through a cycle of development in the invertebrate host, a careful search should be made for a cyclical metamorphosis in the blood and organs of the vertebrate host.

\section{Concluding Remarks.}

Our object, in writing this review, is to show that, as there is at present endless confusion regarding such important problems as the life cycles of trypanosomes and the methods by which they are transmitted, it is quite impossible for anyone who has not made a special study of these parasites to attempt to analyse the great mass of conflicting statements, and to differentiate between those that are erroneous and those that are correct.

As we have devoted particular attention to these parasites, more especially to those harmless forms which are parasitic in the alimentary tracts of arthropods and leeches, we have felt justified in criticising the conclusions arrived at by Woodcock and others, pointing out why we consider their deductions are faulty. The preparation of this paper has entailed a great deal of labour, owing to the fact that the observations

1 Some confirmation of these observations has recently been brought forward by Chagas (1909). 
already recorded are scattered in many journals, a few of which we have not been able to consult : further, in many instances the conclusions of one observer are totally different to those of another, although presumably both were studying the same parasite. The observations on the flagellates of insects recorded by most observers are so incomplete and disconnected that, although we have made a special study of the life cycles of several species of Herpetomonas and Critlidia, it has been quite impossible to place all the observations in any systematic order and to harmonise them with our results. We (1908) have elsewhere suggested that these simple parasites have a definite life history which may conveniently be divided into three stages, pre-flagellate, flagellate and postflagellate. We believe, that if they are studied along these lines, the many forms, which at present it is impossible to understand, will eventually be found to fit into their right places in the life cycles of the parasites. One example here will suffice. We have already noted that Chatton and Alilaire (1908) have recently described two flagellates from Drosophila confusa ; one of these is obviously a typical Herpetomonas, and the other, which was chiefly found in the malpighian tubes of the fly, we believe is a Crithidia. Chatton and Alilaire however consider it is a trypanosome somewhat like $T$. dimorphon, Dutton and Todd. On referring to the authors' figures of this flagellate we find it has all the characteristics of an insectan Crithidia such as we (1909) have recently defined; its large blepharoplast should be particularly noted. In fig. 8 we note the flagellum does not appear to pass right up to the blepharoplast, which is almost at the posterior end. This figure should be compared with our drawings of the post-flagellate stage of $C$. ctenophthalmi where a very similar appearance will be seen in the case of the flea crithidia. We believe then that the two flagellates of Drosophila confusa are quite distinct, and that one is Herpetomonas, while the other is a Crithidia. It is well known that both Herpetomonas and Crithidia may be found in the same insect. From a study of some of the figures of C. drosophila we believe Chatton and Alilaire are dealing with the postflagellate stage of the parasite. Figs. 4, 5 and 6 depict a typical Crithidia in which the blepharoplast tends rather to lie behind the nucleus (see our figure of $C$. haemaphysalidis). In studying these parasites of insects it is of the utmost importance to first ascertain how they are transmitted from one insect to another; having found this out the complete life cycle will in most cases be readily understood. 
In conclusion we wish to state that we have found the Bulletin of the Sleeping Sickness Bureau, kindly sent to us by the Director of the Bureau, of great help. This monthly publication is valuable as it contains aecurate summaries of all the papers dealing with Sleeping Sickness and the flagellates of tsetse flies.

\section{REFERENCES.}

Bagshawe, A. G. (1909). Bulletin of the Sleeping Sickness Bureau. No.5. March. p. 182.

Billet, A. (1904). Sur le Trypanosoma inopinatum de la grenouille verte d'Algérie et sa relation possible avec les Drepanidium. Compt. rend. Soc. Biol., Lvir., pp. 161--4, 16 figs., with note by MesniL, p. 164.

- (1904). Culture d'un Trypanosome de la grenouille chez une hirudinée; relation ontogénique possible de ce Trypanosome avec une Hémogrégarine. Compt. rend. Acad. Sci., cxxxviI., pp. 574-6.

Bouet, G. (1907). Les trypanosomiases animales de la Basse-Côte d'Ivoire. Annal. Inst. Pasteur, xxi., pl. 468-74.

Breinl, A. and Kinghorn, A. (1906). An experimental Study of the Parasite of African Tick Fever (Spirochaeta duttoni). Liverpool Sch. Trop. Med., Memoir XXI.

Bruce, D. (1896). Further report on Tsetse Fly Disease or Nagana in Zululand. $69 \mathrm{pp}$. Folio. London : Harrison \& Sons.

- (1903). Appendix to Further Report on Tsetse Fly Disease or Nagana in Zululand. 21 pp. Folio. London.

Bruce, D. and Nabarro, D. (1903). Progress Report on Sleeping Sickness in Uganda. Reports of the Sleeping Sickness Commission of the Royal Society, No. 1.

Bruce, D., Nabarro, D. and Greig, E. D. W. (1903). Further Report on Sleeping Sickness in Uganda. Reports of the Sleeping Sickness Commission, No. 4.

Brumpt, E. (1904). Contribution à l'étude de l'évolution des Hémogrégarines et des Trypanosomes. Compt. rend. Soc. Biol., LvII., pp. 165-7.

- (1906). Sur quelques espèces nouvelles de Trypanosomes parasites des poissons d'eau douce; leur mode d'évolution. Ibid. LX., pp. 160-2.

- (1906). Mode de transmission et évolution des Trypanosomes des poissons; description de quelques espèces de Trypanoplasmes des poissons d'eau douce; Trypanosome d'un crapaud Africain. Ibid. LX., pp. 162-4.

-(1906). Expériences relatives au mode de transmission des Trypanosomes et des Trypanoplasmes par les hirudinées. Ibid. LxI., pp. $77-9$.

— (1906). Rôle pathogène et mode de transmission du Trypanosoma inopinatum Ed. et Et. Sergent; Mode d'inoculation d'autres Trypanosomes. Ibid. LxI., pp. 157-9.

- (1907). De l'hérédité des infections à Trypanosomes et à Trypanoplasmes chez les hôtes intermédiaires. Ibid. LxIII., p. 176.

— (1908). De l'origine des hémoflagellés du sang des vertébrés. Ibid. LxIV., p. 1046. 
Cazalbou, L. (1906). Expériences d'infection de trypanosomiase par Glossina palpalis infectées naturellement. Compt. rend. Acad. Sci., cXLIII., pp. 435-7.

Chagas, C. (1909). Neue Trypanosomen (vorläufige Mitteilung). Archiv f. Schiffsu. Tropen-Hyg., Bd. xiII., pp. 120-2.

Chatton, E. et Alilaire, E. (1908). Coexistence d'un Leptomonas (Herpetumonas) et d'un Trypanosoma chez un muscide non vulnérant, Drosophila confusa Staeger. Compt. rend. Soc. Biol., Lxiv., p. 1004. Fig. in text.

Dofrkin, F. (1909). Probleme der Protistenkunde, 1. Die Trypanosomen, ihre Bedeutung für Zoologie, Medizin und Kolonialwirtschaft. Gustav Fischer : Jena.

Donoran, C. (1909). Annual Report and Statistics of the Government General Hospital, Madras, for the year 1909. Issued from the Government Press, Madras, 15th May, 1909, pp. 28-32.

Dutron, J. E. and Todd, J. L. (1907). A note on the morphology of Spirochaeta duttoni. Lancet, pp. 1523-5.

Dutron, J. E., Tond, J. L. and Hannington, J. W. B. (1907). Trypanosome Transmission Experiments. Annal. Trop. Med. and Parasit., No. 2, pp. 201-29.

Fantham, H. B. (1907). Spirochaeta (Trypanosoma) balbianii (Certes), its Movements, Structure and Affinities; and on the occurrence of Spirochaeta anodontae (Keysselitz) in the British Mussel, Anodonta cygnea. Ann. Mag. Nat. Hist., ser. 7, Vol. xIx., pp. 493-501 (Preliminary Communication).

- (1908). Spirochaeta (Trypanosoma) balbianii (Certes) and Spirochaeta anodontae (Keysselitz): their Movements, Structure and Affinities. Quart. Journ. Micr. Sci., LII., pp. 1-73, 3 pts.

Francis (1903). Bull. No. 11, Hyg. Lab. U. S. Pub. Health and Marine Hosp. Serv.

Gray, A. C. H. and Tulloch, F. M. G. (1905). The multiplication of Trypanosoma gambiense in the alimentary canal of Glossina palpalis. Reports of the Sleeping Sickness Commission of the Royal Society, No. 6 (1906), pp. 282-7, 4 figs.

Greig, E. D. W. and Gray, A. C. H. (1905). Continuation Report on Sleeping Sickness in Uganda. Reports of the Sleeping Sickness Commission of the Royal Society, No. 6, pp. $1-273$.

JürgENS (1903). Archiv f. Hyg., v., 42, p. 265.

Keysselitz, G. (1906). Generations- und Wirtwechsel von Trypanoplasma borreli Laveran et Mesnil. Archiv f. Protistenkunde, vir., pp. 1-74, 162 figs.

Keysselitz, G. und Mayer, H. (1908). Zur Frage der Entwickelung von Trypanosoma brucei in Glossina fusca. Archiv f. Schiffs- u. Tropen-Hyg., Bd. XII., pp. 532--5.

KLEINE (1909). Positive Infectionsversuche mit Trypanosoma brucei durch Glossina palpalis. Deutsche med. Wochenschr., 18. März, pp. 469-70. (1909). Weitere wissenschaftliche Beobachtungen über die Entwicklung von Trypanosomen in Glossinen. Deutsche med. Wochenschr., May, pp. 924-5.

Косн, R. (1905). Vorläufige Mitteilungen über die Ergebnisse einer Forschungsreise nach Ostafrica. Deutsche med. Wochenschr., xxх1., pp. 1865-9, 24 figs.

- (1905). Ueber die Unterscheidung der Trypanosomenarten. Sitzungsber. d. Königl. preuss. Akad. d. Wiss., Xuvi., pp. 957-62. 
Косн, R. (1906). Ueber den bisherigen Verlauf der deutschen Expedition zur Erforschung der Schlafkrankheit in Ostafrika; Sonderbeilage zu No. 51 der Deutschen med. Wochenschr, pp. 1-8.

- (1907). Bericht über die Tätigkeit der deutschen Expedition zur Erforschung der Schlafkrankheit bis zum 25 November, 1906. Ibid. xxxIIr., pp. 49-51.

Krzysztalowicz, F. et Siedlecki, M. (1908). Étude expérimentale de la Syphilis; Morphologie de Spirochaeta pallida. Bull. Acad. Sci. Cracovie, pp. 173-232, 2 plts.

Laveran, A. (1909). Discussion on A. Billet's paper, Sur un cas de Clou de Biskra. Bull. Soc. P'ath. Exot., T. 11, No. 2, pp. 92-3.

Laveran, A. et Mesnil, F. (1904). Trypanosomes et Trypanosomiases.

LÉger, L. (1902). Sur un flagellé parasite de l'Anopheles maculipennis. Compt. rend. Soc. Biol., LIv., pp. 354--6, 10 figs.

- (1903). Sur quelques Cercomonadines nouvelles ou peu connues parasites de l'intestin des insectes (note préliminaire). Archiv f. Protistenkunde, II., pp. 180-9, 4 figs.

(1904). Sur les hémoflagellés du Cobitis barbatula L. Compt. rend. Soc. Biol., LVII., pp. 344-7.

(1904). Sur un nouveau flagellé parasite des tabanides. Ibid. Lvir., pp. 613-5, 6 figs.

— (1904). Sur les affinités de l'Herpetomonas subulata et la phylogénie des trypanosomes. Ibid. LVII., pp. 615--7.

Mezincescu, D. (1909). Evolution des Ookynètes d'Haemoproteus dans l'intestin des moustiques. Compt. rend. Soc. Biol., T. Lxvi., pp. 328-9.

Minchis, E. A. (1908). Investigations on the development of Trypanosomes in tsetse flies and other Diptera. Quart. Journ. Microsc. Sci., LII., part 2, pp. $159-260,6$ plts.

_ (1908). Note on the Polymorphism of Trypanosoma gambiense. Parasitology, I., No. 3, p. 236, Plate xvII.

Minchin, E. A., Gray, A. C. H. and Tolloch, F. M. G. (1906). Glossina palpalis in its relation to Trypanosoma gambiense and other Trypanosomes (Preliminary Report). Proc. Roy. Soc., Ser. B, LxxviII., pp. 242-58, 1 figs., 3 plts.

MiYajIma (1907). The cultivation of bovine Piroplasma. Philippine Jour. Sci., xI. (Med. Sc.), p. 3.

Nicolle, C. (1907). Etude microscopique de cinq cas de bouton d'Orient. Arch. Inst. Past. Tunis, III., pp. 130-41.

(1908). Sur trois cas d'infection splénique infantile à corps de Leishman observés en Tunisie. Arch. Inst. Pasteur, Tunis, pp. 3-26, 1 plate.

-_- (1908). Culture des corps de Leishman isolés de la rate dans trois cas d'anémie splénique infantile. Bull. Soc. Path. Exot., T. I., pp. 121-6, fig. in text.

(1908). Nouvelles acquisitions sur le Kala-Azar: Cultures; inoculations au chien ; étiologie. Compt. rend. Acad. Sci., T. cuxvi., p. 498.

(1908). Reproduction expérimentale du Kala-Azar chez le Chien. Origine canine probable de cette affection. Bull. Soc. Path. Exot., T. I., pp. 188-90. (1908). Culture du parasite du Bouton d'Orient. Compt. rend. Acad. Sci., cxL., p. 842. 
NicoLLE, C. (1908). Quelques faits nouveaux relatifs au Kala-Azar infantile. Ibid. T. I., No. 10, pp. 602-5.

Nicolle, C. et Cassuto, E. (1908). Infection splénique infantile à corps de Leishman-Donovan. Ses rapports avec le Kala-Azar et l'anémie splénique infantile. Presse Médicale, pp. 89-91, fig. in text.

Nicolle, C. et Comte, C. (1908). Origine du Kala-Azar. Compt. rend. Acad. Sci., CLXVI., p. 789.

Novy, F. G. (1906). The Trypanosomes of Tsetse Flies. Journ. Infect. Dis., III., pp. 394-411, 3 plts.

(1907). The Rôle of Protozoa in Pathology. Proceed. Path. Soc. Philad., pp. $1-27$.

(1908). Successful canine infection with cultures of Leishmania infantum (C. Nicolle). Journ. Americ. Med. Assoc., 41, pp. 1423-4.

Novy, F. G. and MacNeal, W. J. On the Trypanosomes of Birds. Journ. Infect. Dis., II., p. 394, 3 plates.

Novy, F. G., MacNeal, W. J. and Torrey, H. N. (1906). Mosquito Trypanosomes. Journ. Hygiene, vi., p. 110.

- (1907). The Trypanosomes of Mosquitoes and other Insects. Journ. Infect. Dis., Iv., No. 2, pp. 223-76, 7 plates.

Nutrall, G. H. F. (1908). Spirochæotosis in Man and Animals. Harben Lectures, No. 2. Journ. Roy. Inst. Pub. Health.

(1909). The Transmission of Trypanosoma lewisi by Fleas and Lice. Parasitology, Vol. 1. 4, pp. 296-301.

Patton, W. S. (1907). Preliminary note on the development of a species of Herpetomonas found in Culex pipiens. Brit. Med. Journ., II., pp. 78-80.

(1907). Annual Report upon the work of the Bacteriological Section of the King Institute of Preventive Medicine.

(1908). The Life-Cycle of a Species of Crithidia parasitic in the intestinal tract of Gerris fossarum Fabr. Archiv f. Protistenkunde, xIr., pp. 131-46.

(1908). Herpetomonas lygaei. Archiv f. Protistenkunde, xII. Bd. 1, pp. 1-18.

(1909). Inoculation of dogs with the parasite of Kala-Azar (Herpetomonas [Leishmania] donovani) with some remarks on the Genus Herpetomonas. Parasitology, I. 4, pp. 311-13.

Patton, W. S. and Strickland, C. (1909). A Critical Review etc. Parasitology, I. 4 , pp. $322-43$.

Prowazek, S. (1905). Studien über Saugetiertrypanosomen. Arbeit. a. d. Kaiserl. Gesundh., XXII.

Robertson, M. (1907). Studies on a trypanosome found in the alimentary tract of Pontobdella muricata. Proc. Roy. physic. Soc., Edinb., xvII., pp. 83-108.

- (1908). A Preliminary Note on Haematozoa from some Ceylon Reptiles. Spolia Zeylanica, Vol. v. Part xx., pp. 178--84.

Ross, R. (1906). Notes on the parasites of mosquitoes found in India etc. Journ. Hygiene, vi., p. 101.

RodBAUD, E. (1907). Transmission de Trypanosoma dinorphon par Glossina palpalis, R. Desv. Annal. Inst. Past., pp. 466-7.

- (1908). Fixation, Multiplication, Culture d'attente des trypanosomes patho- 
gènes dans la trompe des Mouches tse-tse. Compt. rend. Acad. Sci., cxivi., p. 423.

Rovbaud, E. (1908). Sur un nouveau flagellé parasite de l'intestin des Muscides au Congo français--Leptomonas mesnili, n. sp. ; nouveau flagellé à formes trypanosomes de l'intestin de muscides non-piquers. Ibid. LIv., p. 1107 ; Lv., p. 29.

- (1908). Infection naturelle de la Trompe des Glossines. Bull. Soc. Path. Exot., I., No. 9, pp. 564-8.

(1909). Recherches biologiques sur les conditions de viviparité et vie larvaire de Glossina palpalis, R. Desv. Compt. rend. Acad. Sci., cxuvir., pp. 195-97.

Row, R. (1909). Cultivation of H. tropica from a case of Delhi Boil. Bombay Medical Congress, Feb. 1909. Brit. Med. Journ., March 20th, p. 746.

Salvin-Moorf, J. E. and Breinl, A. (1907). Note on the Life-History of the Parasite of Sleeping Sickness. Lancet, May 14th, p. 1219.

(1908). The Cytology of the Trypanosomes. Ann. Trop. Med. and Parasit., Vol. I., No. 3.

(1908). The Life-History of Trypanosoma equiperdum. Proc. Roy. Soc., Ser. B, Vol. viII., pp. $288-97$.

Salvin-Moore, J. E., Breinl, A. and Hindle, E. (1908). The Life-History of Trypanosoma lewisi. Ann. Trop. Med. and Parasit., Vol. II., No. 3.

Schaudinn, F. (1904). Generations- und Wirtwechsel bei Trypanosoma und Spirochaeta (vorläufige Mitteilung). Arbeit. a. d. Kaiserl. Gesundh., xx., pp. 387-439, 20 figs.

Schneider, J. E. J. (1909). Discussion on A. Billet's paper. Bull. Soc. Path. Exot., T. II., No. 2, pp. 91-2.

Stuhlmann, F. (1907). Beiträge zur Kenntniss der Tsetsefliege (Glossina fusca, und Gl. tachinoides). Arbeit. a. d. Kaiserl. Gesundh., xxvi., pp. 301-83.

Swivgle, L. D. (1909). A study on the life history of a Flagellate (Crithidia melophagi, n. sp.) in the alimentary tract of the Sheep-tick (Melophagus ovinus). Journ. Infect. Dis., vi., pp. 98-121. Pls. III. IV. and v.

Thomson, J. D. (1908). Cultivation of the Trypanosome found in the blood of the Gold-fish. Journ. Hygiene, viIr., pp. $75-82$.

Wenyon, C. M. (1908). A Trypanosome and Haemogregarine of a Tropical American Snake. Parasitology, i. 4, pp. 314-16.

Woodcock, H. M. (1906). The Haemoflagellates; A Review of Present Knowledge relating to the Trypanosomes and Allied Forms. Quart. Journ. Micros. Sci., L., p. 224.

- (I. 1909). "The Haemoflagellates and allied forms." Article in Treatise on Zoology, Section G, part I, pp. 193-273; edited by Sir E. RaY Lankester.

_- (1909). On the Occurrence of Nuclear Dimorphism in a Halteridium parasitic in the Chaffinch, and the probable connection of this parasite with a Trypanosome. Quart. Journ. Micros. Sci., LIII., part 2, pp. 339-49. 


\section{APPENDIX.}

Since the above review was written three papers dealing with trypanosomes and allied flagellates have been published which it will be necessary to refer to shortly here. Bruce and his collaborators (1909) have repeated Kleine's experiments (see p. 107) with 'T. gambiense and G. palpalis, and have found that this fly is infective after 16,19 , and 22 days subsequent to its ingesting the trypanosome. This discovery only goes to show that during this period $T$. gambiense remains alive and retains its virulence while in the fly, but it by no means proves it undergoes a developmental cycle. There is at present too great a tendency to conclude that certain trypanosomes must pass through developmental cycles in tsetse flies, for we find that in a leading article on Bruce's recent work in the British Medical Journal (May 15th, 1909, page 1200) it is stated, "the fact that trypanosomes develop in tsetse flies may now be said to be established." We are not told what is meant by the term "develop," presumably the writer means a sexual cycle; as far as we are aware there is no proof that trypanosomes pass through any such cycle. To say then that $T$. gambiense has a developmental cycle in $G$. palpalis is pure assumption and the loose usage of the terms "develop" and "developmental cycle" are misleading and are to be strongly deprecated.

We will now consider the possible explanation of the long period of non-infectivity of tsetse flies: (1) From our knowledge of the life-cycles of Herpetomonas and Crithidia it is conceivable that $T$. gambiense, in addition to the well-known flagellate stage, is ingested by $G$. palpalis in a non-flagellate form, as has been described by Salvin-Moore and Breinl, and that this stage of the parasite becomes a flagellate during the period of non-infectivity; it is however not known whether these forms occur in the peripheral blood of sleeping sickness cases. Whether this is so or not, it would quite well explain the long period of non-infectivity of the flies. (2) The parasites after being ingested by the fly undergo a sexual cycle, perhaps after Schandinn's plan for T. noctuae, and then make their way up to the proboscis of the fly. We have however shown above that this cycle is most improbable. (3) The trypanosomes, after remaining from 14 to 16 days in the stomach of the fly, make their way to its proboscis without passing through any sexual cycle; during this period they may undergo equal and unequal longitudinal division. These seem to 
us to be the probable solutions of Kleine and Bruce's work, and at present we are inclined to consider the last explanation as the most likely one.

It can be readily understood that any multiplication forms of T. gambiense may be quite easily missed, especially when we consider that G. palpalis is nearly always infected with C. grayi and C. tullochi. This would at once explain why previous observers have failed to find T. gambiense in this fly several days after it has fed on infected blood. The multiplication forms of T.gambiense are not even known and the close similarity of the crithidia to trypanosomes would obviously lead to great confusion unless the life cycles of these natural flagellates are first carefully worked out.

Up till the present it has been generally believed that $T$. gambiense is transmitted mechanically, that is to say the trypanosomes which remain in the fly's proboscis are inoculated into a fresh host just as if they had been injected with a hypodermic needle. This method of infection must however be the exception, as the majority of the trypanosomes are undoubtedly taken into the stomach of the fly, and some time must necessarily elapse before they can find their way back again to its proboscis; there is no evidence to show that during this period the trypanosumes pass through a sexual cycle. We would again point out that G. palpalis is known to be frequently infected with two natural flagellates, and that unless their life-cycles are completely worked out it will be impossible, even with bred flies, to study the changes T. gambiense undergoes in G. palpalis.

The next paper is a preliminary communication by Chagas (1909) who describes two new trypanosomes, one $T$. minasense from a monkey Hapale penicillata, and the other T. cruzi from a bug (Conorrhinus). The non-flagellate stages of $T$. minasense are found in the lungs of infected monkeys; each parasite, according to Chagas, contains eight small organisms each provided with a bilobed nucleus; on their separating they penetrate the red blood corpuscles and become typical trypanosomes. Chagas considers this represents the process of schizogony. Six to eight hours after a bug (Conorrhinus) has fed on an infected monkey the trypanosomes (T. cruzi?) in its stomach lose their undulating membrane and flagellum; the indifferent forms then multiply and cysts appear which Chagas considers represent a form of sexual development. In the proctodaeum of the bug crithidia-like forms were found in large numbers. Adult parasites resembling full grown trypanosomes were seen in the body cavity of the bug. It is not quite clear as to whether the 
author considers the flagellates found in the species of Conorrhinus are developmental forms of $T$. minasense or stages of some other vertebrate trypanosome. We know of a species of Conorrhinus (C. rubrofasciatus) in Madras in which Donovan (1909) has found a true crithidia. It is therefore most probable that $T$. cruzi is also a natural crithidin of the bug and it would be important to know how it is transmitted from one bug to another. There is no proof in Chagas' preliminary note to show that $T$. cruzi is a vertebrate trypanosome.

The last paper we wish to refer to is by Swingle (1909); this author describes in some detail the life-cycle of Crithidia melophagia Flu.; he has come to the conclusion that this flagellate has nothing to do with the sheep, but is a true parasite of Melophagus ovinus. We entirely agree with this view and consider it is the only possible explanation of its occurrence in the alimentary tract of the sheep "ked." Swingle brings forward some sound evidence to show that this crithidia is most probably transmitted through the eggs of the insect, as he has been able to find its post-flagellate stages in sections of the ovaries. There appears however to be an attempt at true cyst formation such as we have described for Crithidia gerridis and Crithidia tabani.

With regard to the biological position of this parasite Swingle considers it is intermediate between crithidia and herpetomonas. We however have no doubt that it is a true crithidia, and exactly answers to our (1909) definition of this genus. Swingle rightly points out that if Novy, MacNeal, and Torrey's (1907) nomenclature is to be followed Crithidia melophagia would be neither a crithidia nor a herpetomonas, for according to the American observers herpetomonas has an undulating membrane. This we cannot agree with; all the herpetomonads we have studied have no undulating membrane, while all the crithidia have. As we have pointed out elsewhere, the American observers' characterisation of the crithidia is based on Léger's unfortunate description of $C$. fasciculata. Donovan (1909), who has studied these parasites under the most favourable conditions, viz. in the alimentary tracts of their hosts, is entirely of our opinion, and we cannot do better than quote his remarks. He says: “There appears to be still a considerable amount of confusion, one may say ignorance, of the three parasitic gevera, Herpetomonas, Crithidia and Trypanosoma; all forms not in possession of an undulatory membrane and a posteriorly placed blepharoplast are loosely called ' herpetomonas forms' or 'wild trypanosomes' (sic). As I have had under observation during the last 18 months a number of these three genera I may be pardoned for my presumption in setting this question on a sounder basis. 
The full grown form of the genus Herpetomonas is characterised by a blepharoplast placed almost at the very extreme anterior end and with no signs of an undulatory membrane. The largest forms are found in this genus, for instance, $H$. muscae-domesticae 70 to $120 \mu$, including the flagellum. This genus occurs in the non-biting flies and plant-frequenting bugs. In Crithidia the blepharoplast is located near and anterior to the nucleus; there is also present what may be called a rudimentary undulatory membrane. The parasites of this genus are found in the gut of the biting flies, in predatory and plant-frequenting bugs, in mosquitoes and in ticks. In Trypanosoma we have the blepharoplast placed at the very extreme posterior end and an undulatory membrane very well developed. These forms are parasitic in the vertebrates." Donovan agrees with us that the type species of the genus Herpetomonas "is not biflagellate as Prowazek has attempted to make out and such individuals are by far the most common kind met with in the gut of some Musca domestica." 